\title{
Controls on the spacing of first-order valleys
}

\author{
J. Taylor Perron, ${ }^{1,2}$ William E. Dietrich, ${ }^{3}$ and James W. Kirchner ${ }^{3,4,5}$ \\ Received 7 January 2008; revised 25 August 2008; accepted 6 October 2008; published 24 December 2008.
}

[1] Many landscapes are composed of ridges and valleys that are uniformly spaced, even where valley locations are not controlled by bedrock structure. Models of long-term landscape evolution have reproduced this phenomenon, yet the process by which uniformly spaced valleys develop is not well understood, and there is no quantitative framework for predicting valley spacing. Here we use a numerical landscape evolution model to investigate the development of uniform valley spacing. We find that evenly spaced valleys arise from a competition between adjacent drainage basins for drainage area (a proxy for water flux) and that the spacing becomes more uniform as the landscape approaches a topographic equilibrium. Valley spacing is most sensitive to the relative rates of advective erosion processes (such as stream incision) and diffusion-like mass transport (such as soil creep) and less sensitive to the magnitude of a threshold that limits the spatial extent of stream incision. Analysis of a large number of numerical solutions reveals that valley spacing scales with a ratio of characteristic diffusion and advection timescales that is analogous to a Péclet number. We use this result to derive expressions for equilibrium valley spacing and drainage basin relief as a function of the rates of advective and diffusive processes and the spatial extent of the landscape. The observed scaling relationships also provide insight into the cause of transitions from rill-like drainage networks to branching networks, the spatial scale of first-order drainage basins, the contributing area at which hillslopes transition into valleys, and the narrow range of width-to-length ratios of first-order basins.

Citation: Perron, J. T., W. E. Dietrich, and J. W. Kirchner (2008), Controls on the spacing of first-order valleys, J. Geophys. Res., 113, F04016, doi:10.1029/2007JF000977.

\section{Introduction}

[2] Landscapes have many self-organized features [Hallet, 1990], which range in size from ripples and dunes [Bagnold, 1941; Kennedy, 1969] to evenly spaced mountain ranges [Eaton, 1982]. Some of the most basic and visually striking scales are associated with the erosional dissection of landscapes into ridges and valleys. To first order, the scale of the topography in such a landscape is defined by the spacing and depth of the valleys, or, equivalently, the width and height of the intervening ridges. It has long been observed that ridges and valleys within a given landscape appear to have a characteristic size. In particular, valley spacing is often quasiperiodic [Gilbert, 1877; Shaler, 1899; Hack and Goodlett, 1960; Hanley, 1977; Hovius, 1996; Talling et al., 1997; Izumi and Parker, 2000; Allen, 2005],

\footnotetext{
${ }^{1}$ Department of Earth and Planetary Sciences, Harvard University, Cambridge, Massachusetts, USA.

${ }^{2}$ Now at Department of Earth, Atmospheric and Planetary Sciences, Massachusetts Institute of Technology, Cambridge, Massachusetts, USA

${ }^{3}$ Department of Earth and Planetary Science, University of California, Berkeley, California, USA.

${ }^{4}$ Swiss Federal Institute for Forest, Snow, and Landscape Research, Birmensdorf, Switzerland.

${ }^{5}$ Department of Environmental Sciences, Swiss Federal Institute of Technology, Zürich, Switzerland.

Copyright 2008 by the American Geophysical Union. 0148-0227/08/2007JF000977
}

so that ridge-and-valley topography appears to have a characteristic "wavelength" (Figures 1 and 2).

[3] Perron et al. [2008] demonstrated the existence of characteristic ridge-valley wavelengths by analyzing twodimensional Fourier power spectra derived from highresolution topographic maps of soil-mantled landscapes, including the landscape in Figure 2, and showing that the spectra contained peaks corresponding to quasiperiodic structures. By comparing the topographic spectra with those of fractal surfaces, Perron et al. demonstrated that such uniform valley spacing is unlikely to occur by chance in random topography.

[4] Uniform spacing is especially apparent among firstorder drainage basins in soil-mantled landscapes [Montgomery and Dietrich, 1992; Dietrich and Montgomery, 1998; Perron et al., 2008], but is observed to occur at scales ranging from meter-scale field and laboratory analogs [Schorghofer et al., 2004] to entire mountain belts [Hovius, 1996; Talling et al., 1997], and in diverse settings that include submarine environments [Orange et al., 1994] and beaches [Schorghofer et al., 2004]. Uniformly spaced erosional valleys have even been observed on Mars (Figure 3). Importantly, uniform valley spacing often occurs in landscapes where bedrock structure and tectonic patterns do not exert a significant control on the locations of valleys, a trend noted by Gilbert [1877] in relation to the "great regularity and beauty" of badlands. This observation, along with the 


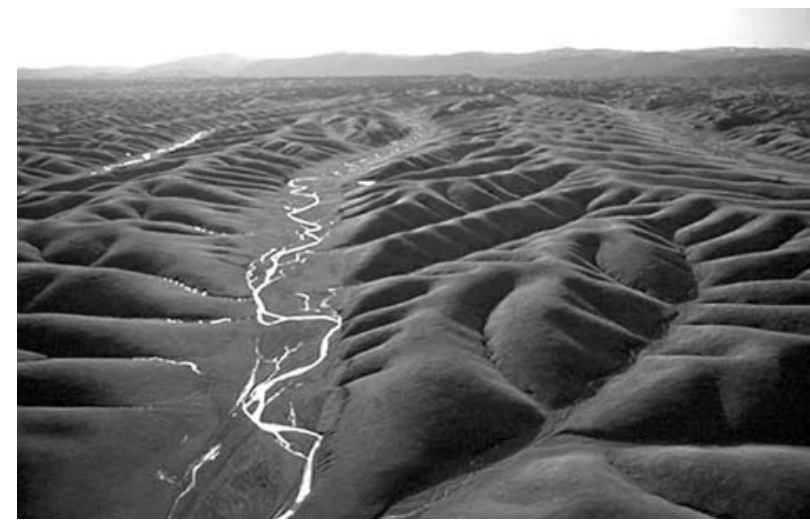

Figure 1. Aerial photograph of a landscape near Orland, California, showing quasiperiodic valley spacing of roughly $100 \mathrm{~m}$. Photo by J. Kirchner.

fact that topography is dynamic and subject to disturbance, implies that the ridge-valley wavelength must emerge from the processes that shape landforms by eroding, transporting and depositing sediment.

[5] Like other prominent patterns in the physical sciences, such as crystal lattices or instabilities that arise at fluid interfaces, spatial periodicities in landscapes must contain fundamental information about the material properties and governing physics of the system that produces them. Yet our ability to interpret this signal is limited by the lack of a welltested mathematical framework for predicting many of the characteristic scales that occur in landscapes. Perusal of the literature on long-term landscape evolution reveals several studies in which physically based numerical models produce landscapes that appear to contain quasiperiodic ridges and valleys [e.g, Howard, 1994a; Kooi and Beaumont, 1996; Densmore et al., 1998; Tucker and Bras, 1998], but it is not clear how this pattern emerges as the topography evolves, how the model equations control the valley spacing, or whether the modeled spacing is consistent with that observed in nature.

[6] A number of previous studies of the erosional development of landscapes have proposed conceptual and quantitative explanations for the characteristic size of drainage basins. One of the earliest was a suggestion by Davis [1892], in response to observations by Gilbert [1877], that the morphologic transition from concave-down topographic profiles near drainage divides to concave-up profiles further downslope corresponds to a transition from erosion dominated by soil creep to erosion dominated by overland flow. This suggestion was developed further by Gilbert [1909]. Later studies quantified the idea that a transition in process dominance might control the extent of valley incision, and ultimately showed that erosional features with a finite, uniform spacing can emerge from a competition between

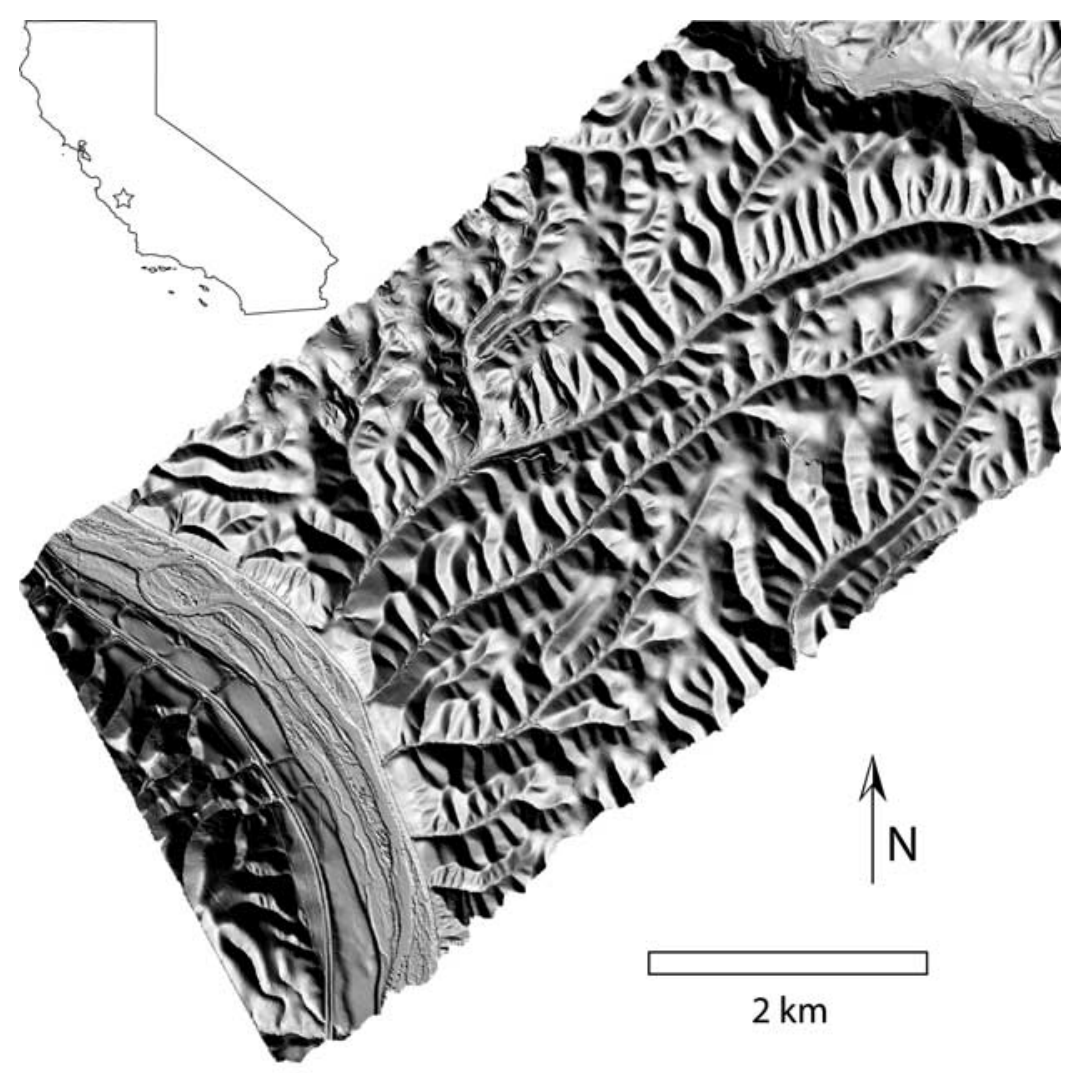

Figure 2. Shaded relief map of a portion of the Gabilan Mesa, California, at approximately $35.9^{\circ} \mathrm{N}$, $120.8^{\circ} \mathrm{W}$. The tributary valleys that drain into the NE-SW trending canyons show a remarkably uniform spacing. The topographic data, with a horizontal resolution of $1 \mathrm{~m}$, were collected and processed by the National Center for Airborne Laser Mapping (NCALM, http://www.ncalm.org). The Salinas River and U.S. Highway 101 are visible to the southwest. 


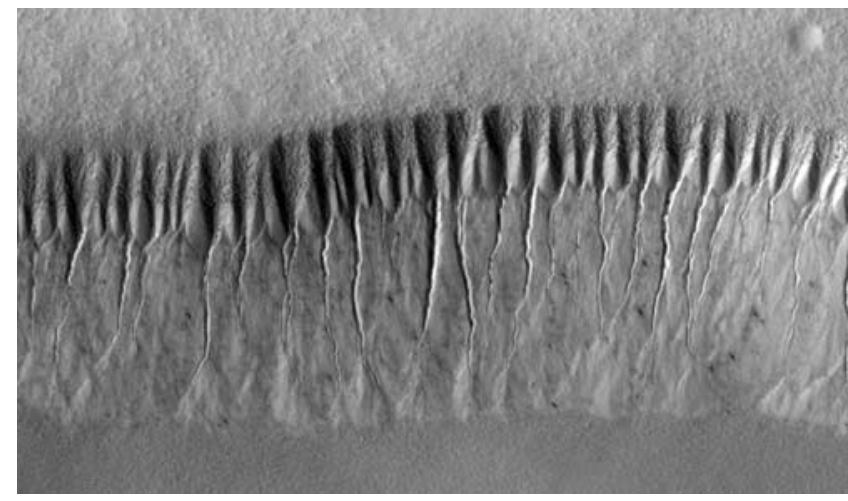

Figure 3. Detail of Mars Orbiter Camera image R0502476 showing evenly spaced erosional features incised into a debris slope at the edge of a depression near $70.7^{\circ} \mathrm{S}$, $355.7^{\circ} \mathrm{W}$. Image width is approximately $6.5 \mathrm{~km}$. The rim of the depression is toward the top of the image; the floor is toward the bottom. Valleys, channels, and depositional fans appear to have been created by repeated debris flows [Malin and Edgett, 2000]. The convex profiles of the intervening ridges may be a signature of slope-dependent creep driven by cyclical deposition and sublimation of ground ice [Perron et al., 2003]. Image courtesy of NASA/JPL/MSSS.

sediment transport processes that amplify perturbations in a topographic surface and processes that damp the perturbations. Kirkby [1971] used a one-dimensional model to show that transport laws describing creep processes generate concave-down topographic profiles, whereas laws describing erosion by channelized flow create concave-up profiles. He noted that these characteristic forms are independent of initial conditions, and that the combined influence of these processes should create profiles that are concave-down near drainage divides and concave up near the toe of the slope. Kirkby also emphasized the importance of two-dimensional topographic convergence or divergence, and its effect on water and sediment fluxes, in the evolution of drainage basins.

[7] This latter topic was explored in considerable detail by Smith and Bretherton [1972] in a study of the incipient development of erosional rills. Smith and Bretherton analyzed the stability of an erodible surface under a sheet of flowing water, and found that if the sediment flux at a given location depends on the flux of water and the topographic gradient, a surface with a concave-up longitudinal profile is unstable with respect to lateral perturbations in the flow, and will inevitably develop erosional channels. Their analysis does not predict a finite rill spacing, because the shortestwavelength instabilities grow fastest, but they posited that introducing a diffusion-like transport term, which describes a process in which sediment flux is proportional to the topographic gradient only, would damp the growth of shortwavelength instabilities and select for an intermediate wavelength. Loewenherz [1991] confirmed this in a general sense by adding an artificial smoothing function and demonstrating that intermediate wavelengths do indeed grow fastest.

[8] Others pointed out that neither slope-dependent transport nor artificial diffusion is necessary to explain finite rill spacing. Izumi and Parker [1995] showed that the inclusion of a free water surface (which was not a feature of the kinematic flow approximation of Smith and Bretherton [1972]) creates backwater effects and Reynolds stresses that prevent the formation of an infinitely narrow, infinitely deep flow, an effect that was anticipated, but not explored, by Smith and Bretherton [1972] and Loewenherz [1991]. Several related studies have investigated rill formation by free-surface flows both analytically [Loewenherz-Lawrence, 1994; Izumi and Parker, 2000] and numerically [Smith and Merchant, 1995; Smith et al., 1997a, 1997b]. Dunne [1980] and Dunne and Aubry [1986] noted, however, that slopedependent transport mechanisms such as rain splash do influence the development of subaerial topography, and could be a significant factor restricting the growth of incipient, short-wavelength erosional channels, as originally suggested by Smith and Bretherton [1972].

[9] These studies provide fundamental insight into landscape evolution by demonstrating that erosional features with a characteristic size can emerge from the dynamics of physical transport mechanisms, including interactions between advective (flux- and slope-dependent) and diffusive (slope-dependent) processes. Yet their results cannot be used to predict the characteristic scales that emerge through the long-term evolution of landforms at scales of $10^{2}-10^{4} \mathrm{~m}$, like those shown in Figure 2, for three main reasons. First, to make the problem analytically tractable, most of these studies have considered small perturbations superimposed on a background topography (often an inclined plane) that does not change. In real landscapes, the erosion of valleys with finite amplitude alters the topography, which feeds back into the rate and spatial pattern of erosion. Second, because most of these studies have examined the development of incipient erosional features rather than the emergence of finite amplitude landforms, the quantities of interest, such as rill spacing, are time-dependent, as intuited by Izumi and Parker [1995] and shown numerically by Smith and Merchant [1995] and Smith et al. [1997b]. Third, these studies investigated the case in which an erodible surface is entirely submerged beneath a shallow flow, and so their mathematical treatment of the problem is not directly applicable to landscapes in which erosion occurs by open channel flow. Thus, despite a considerable body of work that has built upon the hypothesis of Davis [1892] and Gilbert [1909], it is unclear whether a competition between advective and diffusive processes is sufficient to explain the scale and spacing of natural drainage basins.

[10] An alternative explanation for the characteristic size of first-order drainage basins is that of Horton [1945], who proposed that the extent of erosional landscape dissection is limited by a threshold for erosion by overland flow, such as a minimum shear stress that must be exceeded to overcome the cohesion of the soil surface, or a minimum contributing area required to outpace infiltration and generate surface runoff. Horton argued that this results in a "belt of no erosion," a region lying within a "critical distance" of drainage divides in which surface runoff is insufficient to cause erosion, that defines the spatial scale at which hillslopes end and valleys begin. He intended for the belt of no erosion to be taken literally, meaning that no erosion whatsoever occurred in the absence of overland flow transport. Although it is now understood that overland flow 
is just one of several mechanisms that can act on slopes, subsequent studies have found empirical support for the existence of a runoff or erosion threshold that influences the location where a stream channel begins [Montgomery and Dietrich, 1988, 1989, 1992; Reid, 1989; Dietrich et al., 1992, 1993; Dietrich and Dunne, 1993; Prosser and Dietrich, 1995], and some of these studies propose that the observed transition from hillslope to valley morphology is controlled by the magnitude of the threshold [Montgomery and Dietrich, 1988, 1989, 1992; Dietrich et al., 1992]. As Dunne [1980] and Kirkby [1993] note, the process competition of Davis [1892] and Gilbert [1909] and the erosion threshold of Horton [1945] are not mutually exclusive mechanisms, and both are likely to exert a partial control on valley morphology in many landscapes. But the relative importance of the two mechanisms in controlling valley spacing is unknown.

[11] Numerical models of landscape evolution have made it possible to investigate the transient development and equilibrium form of topography that develops under the combined influence of hillslope and fluvial processes. Firstorder drainage basins with a characteristic size do emerge in many of these models [e.g., Ahnert, 1976, 1987; Kirkby, 1986; Willgoose et al., 1991b; Tarboton et al., 1992; Howard, 1994a; Tucker and Bras, 1998], and a number of studies have shown that such characteristic scales vary systematically with the rates of the dominant erosion and transport processes. Some of these studies have focused on the scale at which hillslopes transition into valleys. Kirkby [1987] used a numerical model to investigate controls on hillslope length for a more general set of process laws than those discussed by Smith and Bretherton [1972], including landsliding. A widely recognized morphologic signature of the hillslope-valley transition is the upslope contributing area at which the topographic slope reaches its steepest point, and then begins to grow gentler with increasing contributing area [Tarboton et al., 1989, 1992; Willgoose et al., 1991d, 1992; Willgoose, 1994b; Howard, 1994a]. Tarboton et al. [1992] related this characteristic area, which is generally thought to correspond to the inflection between a concave-down hillslope and a concave-up valley, to the transition in landform stability discussed by Smith and Bretherton [1972]. Several authors have shown that numerical models reproduce this slope-area transition, and have proposed expressions for the characteristic area based on the model equations [Willgoose et al., 1991d; Howard, 1994a, 1997; Moglen et al., 1998; Tucker and Bras, 1998]. A quantity closely related to the slope-area transition is drainage density, defined as the total length of channels per unit area of the landscape. Several studies have used numerical landscape evolution models to systematically investigate variations in drainage density in response to different process rates and laws, including erosion thresholds and the competition between advective and diffusive processes [Willgoose et al., 1991d; Howard, 1997; Moglen et al., 1998; Tucker and Bras, 1998].

[12] There are, however, important differences between the characteristic scales explored by this body of previous work and the characteristic spacing of ridges and valleys. The slope-area transition is correlated with the spatial scale at which first-order valleys begin, but it does not uniquely specify their overall size or spacing. Drainage density provides a spatially averaged measure of the concentration of valleys, but it does not uniquely specify their spatial arrangement. Thus, predictions of drainage density and source area cannot directly predict valley spacing, and the relative influence of erosion thresholds and process competition on valley spacing must be evaluated independently. Recent studies have begun to advance toward this goal [Simpson and Schlunegger, 2003], but there presently is no widely accepted framework for predicting the characteristic spacing of ridges and valleys in natural landscapes.

[13] This paper has three goals: (1) to determine how uniform valley spacing, one of the most salient characteristics of ridge-and-valley topography, emerges as a landscape evolves from an initial condition toward a topographic equilibrium; (2) to evaluate the relative importance of the two hypothesized controls on the scale and spacing of valleys (process competition versus erosion threshold); and (3) to identify quantitative relationships between first-order landscape properties, including valley spacing, and the rates of the erosion and transport processes that shape the landscape. We begin by presenting a numerical landscape evolution model based on a widely used equation that incorporates a competition between advective erosion and diffusive transport, as well as an erosion threshold. We then use dimensional analysis to derive hypothesized scaling relationships between valley spacing and the terms in the governing equation. Finally, we conduct a set of numerical experiments that investigates the proposed scaling relationships, and use the results of these experiments to evaluate the relative importance of the process competition and the stream incision threshold in controlling valley spacing and relief. We conclude by relating our scaling law to previously proposed expressions for the characteristic area of the hillslope-valley transition.

\section{Landscape Evolution Model}

\subsection{Governing Equation}

[14] The derivation of the governing equation closely follows that of Howard [1994a, 1997, 1999] and Tucker and Slingerland [1996, 1997]. For a sediment-mantled topographic surface with elevation $z(x, y)$ measured relative to a fixed base level, conservation of mass requires that

$$
\rho_{s}\left(\frac{\partial z}{\partial t}+\nabla \cdot \mathbf{q}_{\mathbf{s}}\right)=\rho_{r} U
$$

where $t$ is time, $\rho_{s}$ and $\rho_{r}$ are the bulk densities of sediment and rock, $\mathbf{q}_{\mathbf{s}}$ is the volume flux of transportable sediment per unit width of the land surface, and $U$ is the rate of change of bedrock elevation relative to base level. Equation (1) assumes that the conversion of bedrock to soil keeps pace with erosion, such that no bedrock outcrops occur.

[15] The total sediment flux, $\mathbf{q}_{\mathbf{s}}$, results from fluxes associated with overland or channelized flow of water, $\mathbf{q}_{\mathbf{c}}$, and mass movement of sediment, $\mathbf{q}_{\mathbf{m}}$ [Dietrich et al., 2003]. If we express the total flux as a sum of these components, then

$$
\nabla \cdot \mathbf{q}_{\mathbf{s}}=\nabla \cdot \mathbf{q}_{\mathbf{m}}+\nabla \cdot \mathbf{q}_{\mathbf{c}}
$$


Mass movement of sediment can result from a variety of processes, ranging from landsliding to grain-scale transport by rain splash. In soil-mantled landscapes with moderate topographic gradients, the dominant process is creep, which is driven by dilational disturbance of granular sediment due to processes such as bioturbation, frost heaving, and wetting/drying. Creep is hypothesized to occur by slopenormal dilation and subsequent vertical settling, with a resultant time-averaged downslope flux that is proportional (but opposite in sign) to the topographic gradient [Culling, 1960, 1963, 1965]:

$$
\mathbf{q}_{\mathbf{m}}=-D \nabla z .
$$

The proportionality constant $D$ has the units of a diffusivity $\left(\mathrm{L}^{2} \mathrm{~T}^{-1}\right)$. Numerous field studies have provided evidence based on morphology [e.g., Nash, 1980; Hanks et al., 1984; Rosenbloom and Anderson, 1994] and cosmogenic nuclide mass balance [Monaghan et al., 1992; McKean et al., 1993; Small et al., 1999] that supports the applicability of equation (3) in a range of climatic settings [Fernandes and Dietrich, 1997]. In steep topography, there is evidence that $\mathbf{q}_{\mathbf{m}}$ increases nonlinearly as the topographic gradient approaches a limiting value of order unity; however, at gradients $\lesssim 0.4$, the difference between the linear model and the nonlinear model is small [Roering et al., 1999, 2001a, $2001 \mathrm{~b}, 2007]$. The model presented here is intended to simulate landscapes in which hillslope gradients are low to moderate and slope failure is insignificant, such that equation (3) is an adequate description of soil mass transport rates.

[16] The effects of surface water flow include detachment of material from the land surface and transport of this detached material. Here we assume that the transport rate is limited by the rate of detachment and sediment entrainment rather than by the transport capacity, a condition often referred to as "supply limited" [Carson and Kirkby, 1972] or "detachment-limited" [Howard, 1994b; Howard et al., 1994] incision. We further assume that most fluvial erosion occurs during storms that produce flows capable of transporting all eroded material over a distance longer than the model domain, such that no redeposition of fluvially eroded sediment occurs. Under these conditions, the divergence of fluvial sediment flux is equal to the detachment rate, $\varepsilon$ [Howard, 1994a],

$$
\nabla \cdot \mathbf{q}_{\mathbf{c}}=\varepsilon .
$$

It is often assumed, following the observations of Howard and Kerby [1983], that detachment-limited incision rates are directly proportional to the shear stress, $\tau$, exerted by the flow on the bed and banks of a channel, and that cohesion of the bed material may lead to a threshold shear stress, $\tau_{c}$, that must be exceeded for erosion to occur. That is,

$$
\varepsilon= \begin{cases}k_{1}\left(\tau-\tau_{c}\right) & \tau>\tau_{c} \\ 0 & \tau \leq \tau_{c}\end{cases}
$$

with $k_{1}$ an empirical constant that gives the time-averaged detachment rate. The bed shear stress for steady, uniform, open channel flow is

$$
\tau=\rho_{w} g R S,
$$

where $\rho_{w}$ is the density of water, $R$ is the hydraulic radius, and $S$ is the water surface slope. The flow velocity $u$ is given by the Manning equation,

$$
u=\frac{1}{N} R^{\frac{2}{3}} S^{\frac{1}{2}}
$$

where $N$ is an empirical roughness factor. Continuity of the flow requires that

$$
Q_{w}=k_{2} R w u,
$$

where $Q_{w}$ is the volume flux of water through the channel cross section, $w$ is the channel width, and $k_{2}$ is a form factor that approaches one as the width-to-depth ratio of the channel increases. Substituting equation (7) into equation (8) and solving for $R$ gives

$$
R=\left(\frac{N Q_{w}}{k_{2} w S^{\frac{1}{2}}}\right)^{\frac{3}{5}}
$$

To express $R$ in terms of the topography, we assume that the water surface slope is the same as the local topographic slope $(S=|\nabla z|)$ and include the empirical relationships [Leopold and Maddock, 1953; Knighton, 1998]

$$
Q_{w}=k_{3} A^{a}
$$

and

$$
w=k_{4} Q_{w}^{b},
$$

where $k_{3}, k_{4}, a$ and $b$ are constants, and $A$ is the horizontal area of the landscape that drains to the point at which $Q_{w}$ and $w$ are measured. We assume that all flow is concentrated into channels with widths given by equation (11). The application of equation (11) to small contributing areas and discharges has some support from field observation and experiments [e.g., Parsons and Abrahams, 1992; Parsons et al., 1994; Abrahams et al., 1994]. Combining equations (6), (9), (10) and (11) to obtain an expression for $\tau$ and substituting into equation (5) yields

$$
\varepsilon=k_{1}\left[\rho_{w} g\left(\frac{N k_{3}^{1-b}}{k_{2} k_{4}}\right)^{\frac{3}{5}} A^{\frac{3}{3} a(1-b)}|\nabla z|^{\frac{7}{10}}-\tau_{c}\right] .
$$

[17] Taken together, equations (2), (3), (4), and (12) give an expression for the total sediment flux divergence, $\nabla \cdot \mathbf{q}_{\mathbf{s}}$, in equation (1). Solving equation (1) for the time derivative and defining $E=\frac{\rho_{r}}{\rho_{s}} U$ (such that $E$ is a rate of change of land surface elevation ${ }^{\rho_{s}}$ relative to base level) yields a single equation for the time evolution of the topography:

$$
\frac{\partial z}{\partial t}=D \nabla^{2} z-K\left(A^{m}|\nabla z|^{n}-\theta_{c}\right)+E,
$$


with

$$
\begin{aligned}
K & =k_{1} \rho_{w} \rho_{s} g\left(\frac{N k_{3}^{1-b}}{k_{2} k_{4}}\right)^{3 / 5}, \\
\theta_{c} & =\frac{k_{1} \rho_{s}}{K} \tau_{c}, \\
m & =\frac{3}{5} a(1-b), \\
n & =\frac{7}{10} .
\end{aligned}
$$

The hypothesis that $\varepsilon$ is proportional to the rate of energy expenditure of the flow, or "stream power" [Seidl and Dietrich, 1992; Seidl et al., 1994], leads to an equation with the same form as equation (13), but with $n=1$ and a factor of $5 / 3$ increase in $m$. These values of $n$, both of which are used in this study, should be considered approximate inasmuch as the Manning equation is empirically derived, though there is some theoretical support for its form [Gioia and Bombardelli, 2002].

[18] Two points about the use of equation (13) to investigate hypothesized mechanisms for producing uniform valley spacing deserve brief explanations. First, an assumption implicit in equation (13) is that both diffusion-like transport and channelized fluvial erosion may occur throughout the landscape. This common assumption [e.g., Howard, 1994a; Willgoose, 1994b; Tucker and Bras, 1998] is appropriate for a landscape in which channelized flow is pervasive, but conversion of bedrock to erodible sediment keeps pace with surface erosion, including in channels. This condition limits the range of landscapes to which the model applies, but permits a clearer understanding of how the competing terms in the governing equation influence valley spacing. Second, because the model does not explicitly include runoff generation, we do not distinguish between the two mechanisms that can contribute to a threshold for fluvial incision: topographic thresholds for runoff production [e.g., Kirkby, 1980; Dietrich et al., 1992; Dietrich and Dunne, 1993], and mechanical strength of the land surface [e.g., Reid, 1989; Prosser and Dietrich, 1995]. We parameterize these effects in terms of a single threshold that limits the spatial extent and magnitude of fluvial incision, $\theta_{c}$, with the understanding that both material strength and the spatial pattern of runoff production can influence this threshold.

[19] Equation (13) is a nonlinear advection-diffusion equation in which the quantity being advected and diffused is elevation. The first term on the right-hand side is a linear diffusion term, which tends to smooth perturbations in a topographic surface. Depending on the sign of the Laplacian of elevation, $\nabla^{2} z$, this term can lead to either a decrease in elevation with time (erosion) or an increase (deposition). The second term is a nonlinear kinematic wave term that causes differences in elevation to propagate across the landscape in the direction of the topographic gradient vector, $\nabla z$ [Luke, 1972, 1974, 1976]. Because it includes $A$, the upslope contributing area, this term tends to amplify perturbations in the topography. The kinematic wave term is nonlinear because $n$ may differ from unity, and also because $A$ is a function of both position and time with nonlocal dependence: as the topography evolves, changes in $A$ can feed back strongly into valley incision. As indicated in equation (5), this term can only cause erosion. The third term is a source term that drives the evolution of the topography: without differential uplift relative to a boundary, derivatives of elevation, and therefore the other two terms on the right-hand side of equation (13), will tend toward zero as the topography diffuses away to form a featureless, level plain.

\subsection{Numerical Method}

[20] As mentioned in section 1, analytic approaches to systems like equation (13) [Smith and Bretherton, 1972; Smith and Merchant, 1995; Smith et al., 1997a, 1997b; Loewenherz, 1991; Loewenherz-Lawrence, 1994; Izumi and Parker, 2000] have mainly focused on small perturbations in a topographic surface, such as the development of incipient channels, for which the governing equations can be linearized. Here, in contrast, we are interested in the finite amplitude ridge-and-valley topography that emerges as a landscape evolves beyond its initial state toward an equilibrium. The strong nonlinearities in equation (13) make an analytic solution for the equilibrium topography intractable, and so, like several previous studies [e.g., Willgoose et al., 1991b, 1991c; Howard, 1994a; Tucker and Bras, 1998], we solve equation (13) numerically.

[21] Our numerical approach differs from many previous landscape evolution models in that it solves a single governing equation (equation (13)) over the entire spatial domain simultaneously, rather than separately evaluating each individual term describing an erosion or transport process and routing sediment explicitly across the landscape.

\subsubsection{Finite Difference Scheme}

[22] We calculate finite difference solutions to equation (13) on a rectangular grid $z_{i, j}$ with grid spacings $\Delta x$ and $\Delta y$ and dimensions $N_{x} \times N_{y}$, such that

$$
\begin{gathered}
z_{i, j}=z\left(x_{i}, y_{j}\right), \\
x_{i}=i \Delta x, \\
y_{j}=j \Delta y, \\
i=0,1,2, \ldots N_{x}-1, \\
j=0,1,2 \ldots N_{y}-1 .
\end{gathered}
$$

In discrete form, equation (13) can be written as

$$
\Delta z=\Delta t[\Phi(z)+\Psi(z)],
$$


with

$$
\begin{aligned}
\Phi(z) & =D\left(\frac{z_{i+1, j}-2 z_{i, j}+z_{i-1, j}}{\Delta x^{2}}+\frac{z_{i, j+1}-2 z_{i, j}+z_{i, j-1}}{\Delta y^{2}}\right) \\
\Psi(z) & =E-\frac{w_{i, j}}{\delta} K\left[A_{i, j}^{m}\left(\frac{\sqrt{s_{1}^{2}+s_{2}^{2}}+\sqrt{s_{3}^{2}+s_{4}^{2}}}{2}\right)^{n}-\theta_{c}\right] \\
s_{1} & =\frac{z_{i+1, j}-z_{i-1, j}}{2 \Delta x} \\
s_{2} & =\frac{z_{i, j+1}-z_{i, j-1}}{2 \Delta y} \\
s_{3} & =\frac{z_{i+1, j-1}-z_{i-1, j+1}}{2 \sqrt{\Delta x^{2}+\Delta y^{2}}} \\
s_{4} & =\frac{z_{i+1, j+1}-z_{i-1, j-1}}{2 \sqrt{\Delta x^{2}+\Delta y^{2}}}
\end{aligned}
$$

[23] The factor $w_{i, j} / \delta$ in equation (15) (where $\delta$ is the grid spacing; in the present study, $\delta=\Delta x=\Delta y$ in all cases), a modification due to Howard [1994a], accounts for the fact that stream channels have a finite width (equation (11)) that is narrower than the grid spacing. Neglecting this factor would assume implicitly that channels have a width $\delta$, and the model solutions would then be resolution-dependent. In this study, we assume for simplicity that $k_{4}=1 \mathrm{~m}$ and $b=0$ in equation (11), noting that future studies intending to apply this model to a specific field site will need to calibrate the channel width function. The values of $k_{4}$ and $b$ do affect the form of the model topography, but using typical measured values that lead to spatially variable channel width would not qualitatively change the results presented here.

[24] The algorithm used to evaluate the drainage area function $A_{i, j}$ is of critical importance. Not all drainage area algorithms are faithful descriptions of both convergent and divergent flow, and thus not all algorithms are well suited to modeling interactions between topographically convergent valleys and topographically divergent hillslopes. The steepest descent or D8 algorithm [O'Callaghan and Mark, 1984] routes flow to only one of a point's eight neighboring points, and is therefore incapable of producing divergent flow. This method is well suited to modeling channelized flow along a valley axis, but tends to artificially enhance fluvial incision rates on divergent hillslopes by producing linear flow accumulation paths where flow should actually diverge [Tarboton, 1997]. Yet there are also situations in which steepest-descent flow routing inhibits convergent flow, such as the incision of incipient valleys in a nearly planar surface, because subtle changes in the topography are not sufficient to cause an increment of $45^{\circ}$ in the drainage direction [Willgoose, 2005]. Multiple flow direction algorithms [e.g., Freeman, 1991; Quinn et al., 1991], which distribute flow to all downslope neighbors in proportion to slope, perform well in divergent topography but inhibit convergent flow [Tarboton, 1997], which artificially retards valley incision. In response to these shortcomings, methods have been proposed that allow both convergent and divergent flow and do not restrict drainage directions to $45^{\circ}$ increments [e.g., Costa-Cabral and Burges, 1994; Tarboton, 1997]. The most efficient of these is the $D \infty$ algorithm of Tarboton [1997], which we use to evaluate $A_{i, j}$.

[25] Pelletier [2004] has proposed that "static" equilibrium solutions to drainage area-dependent landscape evolution models, in which $\partial z / \partial t=0$ for all $(x, y)$, are an artifact of steepest descent flow routing, whereas numerical meth- ods based on multiple flow directions produce persistently migrating drainage networks like those observed in some physical experiments [Hasbargen and Paola, 2000]. In contrast, we find that a flow routing method in which flow directions are not restricted to discrete increments can generate deterministic numerical solutions with stable drainage divides (see section 5.1), a result also obtained by Moglen and Bras [1995]. One possible explanation for this difference is that Pelletier [2004] uses a limiting slope gradient to account for hillslope processes, which episodically introduces localized changes in elevation that can significantly alter flow directions. It has previously been shown that such stochastic effects can cause persistent drainage migration in numerical models that incorporate landsliding [Densmore et al., 1998]. We have also found that the inclusion of a threshold $\left(\theta_{c}>0\right)$ can make the criterion for reaching a deterministic equilibrium more restrictive than the criterion for stability of the numerical scheme (equation (17)); that is, smaller time steps may be required. It is possible that real geomorphic thresholds produce persistently migrating drainage networks in nature, but this does not appear to be an inevitable consequence of the flow routing method.

[26] Equation (15) consists of a linear operator $(\Phi)$ and a nonlinear operator $(\Psi)$. To solve it forward in time, we use a splitting method that evaluates these operators in separate fractional steps:

$$
\begin{aligned}
\Delta z^{*} & =\Delta t \Psi\left(z^{\kappa}\right), \\
z^{\kappa+\frac{1}{2}} & =z^{\kappa}+\frac{\Delta z^{*}}{2}+\frac{\Delta t}{2} \Psi\left(z^{\kappa}+\Delta z^{*}\right), \\
z^{\kappa+1} & =z^{\kappa+\frac{1}{2}}+\frac{\Delta t}{2}\left[\Phi\left(z^{\kappa+1}\right)+\Phi\left(z^{\kappa}\right)\right],
\end{aligned}
$$

where $\kappa$ denotes the time step. The first fractional step (16a) and (16b) is a second-order Runge-Kutta scheme. The second fractional step (16c) is a Crank-Nicolson scheme, which we evaluate with an alternating direction implicit (ADI) method [Press et al., 1992]. The combination of the two steps is accurate to second order in space and time. The Crank-Nicolson step used to evaluate the diffusion term is unconditionally stable, and so the stability of the entire method is governed by that of the wave term. In general, the stability of explicit solutions to wave equations is subject to the Courant-Friedrichs-Lewy (CFL) stability criterion, which for the nonlinear wave term in equation (13) is

$$
\frac{\sqrt{2} K A^{m}|\nabla z|^{n-1} \Delta t}{\delta} \leq 1 .
$$

For each model run, we specify $K, m$, and $\delta$, and select a value of $\Delta t$ that satisfies equation (17) over the entire grid for the duration of the run.

\subsubsection{Spatial Domain, Initial Conditions, and Boundary Conditions}

[27] The rectangular grid is intended to simulate a ridgeline bounded on two sides ( $y$ boundaries) by stream chan- 


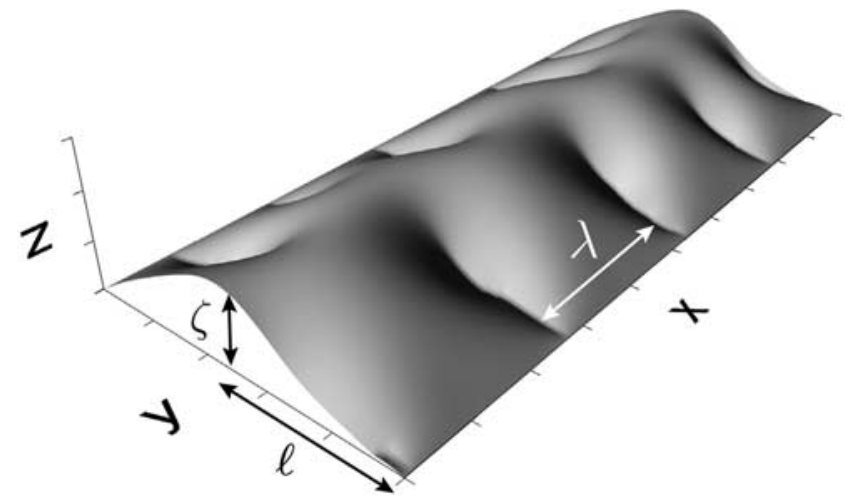

Figure 4. Illustration of the model domain and the three length scales used to measure the topography: $\lambda$, the spacing between adjacent valleys; $\ell$, the horizontal basin length, which is equal to the distance from the central divide to the $y$ boundaries; and $\zeta$, the elevation of the central divide above the $y$ boundaries.

nels (Figure 4). The assumption of detachment-limited conditions implies that these streams are capable of transporting all sediment delivered to them. The incision rate of the bounding stream channels is equal to the rate of surface uplift, such that $\left.\frac{\partial z}{\partial t}\right|_{j=0, N y-1}=0$. This boundary condition is specified numerically by setting

$$
\begin{gathered}
\left.\nabla^{2} z\right|_{j=0, N_{y}-1}=0, \\
\left.\nabla z\right|_{j=0, N_{y}-1}=0, \\
\left.E\right|_{j=0, N_{y}-1}=0 .
\end{gathered}
$$

The $x$ boundaries of the grid are periodic, such that the model ridgeline extends infinitely in the $x$ direction and has topography that repeats with a period of $N_{x} \Delta x$. The parameters $D, K, E, m, n$ and $\theta_{c}$ are uniform in space and time.

[28] The initial condition consists of a low-relief $(\sim 1 \mathrm{~m})$, pseudofractal surface generated by taking the inverse Fourier transform of a two-dimensional, red noise power spectrum. The $y$ boundaries of this surface are levelled to prevent the outlets of stream channels from becoming fixed to certain locations. The iteration proceeds forward in time until $\Delta z_{i, j} / \Delta t=0$ (to within machine precision) for all $i, j$.

\subsection{Resolution Tests}

[29] To test the sensitivity of model solutions to the spatial and temporal resolutions, we performed two sets of runs: one in which only $\Delta t$ was varied, and a second in which only $\delta$ was varied. Model runs using the same initial condition produced identical equilibrium solutions for 10 years $\leq \Delta t \leq 1000$ years (Figure 5a).

[30] When varying $\delta$, it was not possible to use the same initial condition for all runs because the dimensions of the grid varied. There is consequently some variability in the solutions for a given $\delta$ (as indicated by the error bars in Figure $5 b$ ), but the results are, on average, the same for
$1 \mathrm{~m} \leq \delta \leq 16 \mathrm{~m}$ : regression of $\lambda$ and $\zeta$ against $\log _{10} \delta^{2}$ yields lines with slopes that are not significantly different from zero (Figure 5b).

\section{Dimensional Analysis}

[31] To understand how the terms in equation (13) control the model topography, we adopt an approach based on dimensional analysis. Many previous studies have discussed morphometric scaling relationships between the dimensions of existing landforms [e.g., Leopold and Maddock, 1953; Hack, 1957; Melton, 1958; Strahler, 1958; Shreve, 1967; Bull, 1975; Church and Mark, 1980]. A smaller number have considered dynamic scaling relationships among the physical processes that drive long-term landscape evolution [Strahler, 1958, 1964; Smith and Bretherton, 1972; Smith et al., 1997a; Church and Mark, 1980; Willgoose et al., 1991a, 1991c; Willgoose, 1994a; Syvitski and Morehead, 1999; Whipple and Tucker, 1999; Tucker and Whipple, 2002; Simpson and Schlunegger, 2003].

[32] The properties of a topographic surface that is a solution to equation (13), including the spacing between adjacent valleys, $\lambda$, and the overall relief, $\zeta$ (Figure 4), should depend on the relative magnitudes of the three terms on the right-hand side, which can be compared by making equation (13) dimensionless. Using $\zeta$ as a characteristic vertical length scale and defining $\ell$ as a characteristic

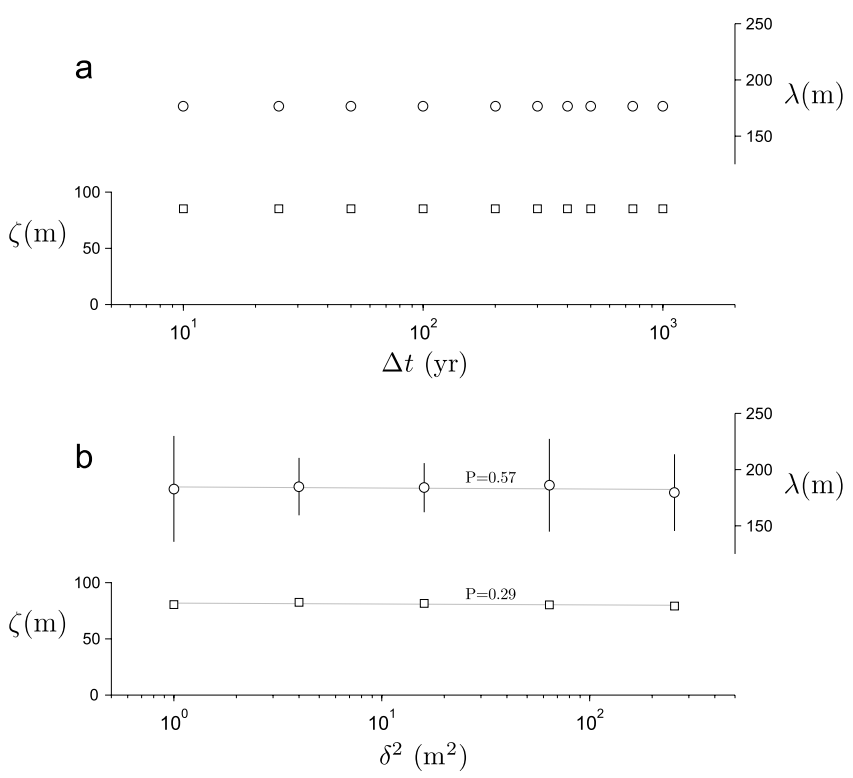

Figure 5. (a) Mean valley spacing, $\lambda$, and relief, $\zeta$, for different time resolutions. All solutions were computed from the same initial surface. The variables $\lambda$ and $\zeta$ are identical for all values of $\Delta t$. (b) Mean valley spacing and relief for different spatial resolutions. Because the grid is two-dimensional, the spatial resolution is proportional to $\delta^{2}$. Because of differing grid dimensions at different spatial resolutions, each simulation used a different (but statistically identical) initial condition. $2 \sigma$ error bars (which are smaller than the symbols for $\zeta$ ) show the resulting variability among the solutions. The slopes of regression lines through the two data sets are not significantly different from zero $(P=0.57$ for $\lambda, P=0.29$ for $\zeta)$. 
horizontal length scale, the dimensionless form of equation (13) is

$$
\frac{\partial z^{\prime}}{\partial t^{\prime}}=D^{\prime} \nabla^{\prime 2} z^{\prime}-\left(K^{\prime} A^{\prime m}\left|\nabla^{\prime} z^{\prime}\right|^{n}-\theta^{\prime}\right)+1
$$

with

$$
\begin{aligned}
z^{\prime} & =\frac{z}{\zeta}, \quad t^{\prime}=\frac{t E}{\zeta}, \quad \nabla^{\prime}=\nabla \ell, \quad A^{\prime}=\frac{A}{\ell^{2}} \\
D^{\prime} & =\frac{D \zeta}{E \ell^{2}}, \quad K^{\prime}=\frac{K \ell^{2 m-n} \zeta^{n}}{E}, \quad \theta^{\prime}=\frac{K \theta_{c}}{E}
\end{aligned}
$$

We take the length scale $\ell$ to be the horizontal length of a drainage basin. Because the topographic divide is always close to the centerline of the grid in the $y$ direction, as shown in Figure 4, drainage basin lengths are generally constrained to be close to one half of the $y$ dimension of the grid $\left(\ell=N_{y} \delta / 2\right)$. We can then define a dimensionless valley spacing, $\lambda^{\prime}=\lambda / \ell$, which is the width-to-length ratio of a drainage basin, and a dimensionless relief, $\zeta^{\prime}=\zeta / \ell$, which is the mean slope of the topography in the $y$ direction.

[33] The dimensionless quantities that contain information about geomorphic process rates are $D^{\prime}, K^{\prime}$ and $\theta^{\prime} . \theta^{\prime}$ describes the magnitude of the erosion threshold relative to the total erosion rate. The other two quantities can be understood in terms of three characteristic timescales: the time required to erode once through the relief is $\zeta / E$; the diffusion time for a feature of size $\ell$ is $\ell^{2} / D$; and the time required for a wave in the topography (such as a knickpoint) with celerity $K \ell^{2 m}(\zeta / \ell)^{n-1}$ to travel a distance $\ell$ is $\ell^{n-2 m}$ $\zeta^{1-n} / K$. Thus, $D^{\prime}$ is the ratio of the erosion timescale to the diffusion timescale, and $K^{\prime}$ is the ratio of the erosion timescale to the advection timescale.

[34] Previous studies have shown that first-order characteristics of the topography such as relief and drainage density vary systematically with parameters in the governing equation [e.g., Kirkby, 1987; Willgoose et al., 1991c; Howard, 1994a, 1997; Moglen et al., 1998; Tucker and Bras, 1998], and so it is reasonable to expect that $\lambda^{\prime}$ will scale with $D^{\prime}, K^{\prime}$, and $\theta^{\prime}$. Although the relationships governing valley spacing may not have the same form as those governing other measures of landscape scale, these previous studies do help us to intuit the signs of some of these relationships. $\lambda^{\prime}$ should be positively correlated with $D^{\prime}$ : higher rates of diffusive sediment transport should lead to wider valley spacing, because the smoothing effect of diffusive transport inhibits valley incision, and because hillslope processes can account for a larger fraction of the total erosion rate. $\lambda^{\prime}$ should be negatively correlated with $K^{\prime}$ : a greater potential for stream incision should lead to narrower valley spacing, because less drainage area is required to erode the land surface at a given rate.

[35] Although numerous studies have shown that an erosion threshold can have a significant effect on river longitudinal profiles [e.g., Snyder et al. 2003] and the overall form of a landscape [e.g., Willgoose et al., 1991c; Howard, 1994a; Rinaldo et al., 1995; Tucker and Slingerland, 1997], the sign of the relationship between $\lambda^{\prime}$ and $\theta^{\prime}$ is difficult to predict. One might expect that a higher threshold for stream incision would widen valley spacing, because the threshold limits both the rate of stream incision and the extent of the landscape over which stream incision can act. The reduction in the stream incision term will lead to steeper topography, however, which will feed back into both the hillslope and fluvial terms [Howard, 1994a]. The net effect on valley spacing is not obvious, nor is the relative importance of the two mechanisms by which the threshold should influence erosion: reducing the rate of stream incision versus limiting its spatial extent.

[36] By analogy to a linear advection-diffusion system, we might additionally expect that it is possible to characterize the system with a single dimensionless quantity that gives the relative magnitudes of the advection and diffusion terms, a quantity similar to a Péclet number, Pe:

$$
\mathrm{Pe}=\frac{K^{\prime}-\theta^{\prime}}{D^{\prime}}=\frac{K}{D}\left(\frac{\ell^{2(m+1)-n}}{\zeta^{1-n}}-\frac{\theta_{c} \ell^{2}}{\zeta}\right) .
$$

For $\theta_{c}=0$, equation (20) reduces to

$$
\mathrm{Pe}=\frac{K \ell^{2(m+1)-n}}{D \zeta^{1-n}}
$$

which is the ratio of a diffusion timescale to an advection timescale, and is therefore directly analogous to a Péclet number in a linear system. Quantities that are conceptually similar, but differ in form, have been derived for transportlimited conditions by Willgoose et al. [1991c] and Simpson and Schlunegger [2003].

[37] Beyond these general expectations, the forms and relative importance of the hypothesized scaling relationships are not apparent, particularly because the scaling parameters depend on relief, $\zeta$, which is not known a priori. Nor is it clear how quasiperiodic ridge-and-valley topography emerges as a landscape develops. We conducted a set of numerical experiments designed to validate the dimensional analysis approach, test for and quantify the hypothesized scaling relationships, and investigate the development of quasiperiodic valley spacing with time.

\section{Numerical Experiments}

[38] The numerical experiments fall into four categories:

\subsection{Time-Dependent Behavior}

[39] To investigate the time evolution of the landscape, including the development of uniformly spaced valleys and the approach to a topographic steady state, we performed a number of model runs in which we recorded and analyzed the topography at each time step.

\subsection{Validation of Dimensionless Quantities}

[40] If the dimensionless numbers in equation (19) adequately predict the behavior of the dimensional governing equation (equation (13)), then the model parameters should influence the model topography only if they affect the dimensionless ratios. That is, if individual parameters $(D$, $K, E$, etc.) change in such a way that the dimensionless ratios do not, the basic properties of the model topography should remain the same. This is, in part, a test of whether the horizontal and vertical length scales we have chosen to characterize the landscape ( $\ell$ and $\zeta$, Figure 4$)$ are appropriate. We calculated model solutions for three different 
Table 1. Model Parameters Used to Obtain the Solutions Displayed in Figures 1-14

\begin{tabular}{|c|c|c|c|c|c|c|c|c|c|c|c|}
\hline Figure & $N_{x}$ & $N_{y}$ & $\delta(\mathrm{m})$ & $\Delta t$ (years) & $t_{\text {final }}(\mathrm{Ma})$ & $E\left(\mathrm{~mm} \mathrm{a}^{-1}\right)$ & $D\left(\mathrm{~m}^{2} \mathrm{a}^{-1}\right)$ & $K\left(10^{-5} \mathrm{~m}^{1-2 m} \mathrm{a}^{-1}\right)$ & $m$ & $n$ & $\theta_{c}\left(\mathrm{~m}^{2 m}\right)$ \\
\hline $5 \mathrm{a}$ & 200 & 100 & 5 & $10-1000$ & 3.00 & 0.05 & 0.005 & 0.1 & 1 & 1 & 0 \\
\hline $5 b$ & 200 & 100 & $1-16$ & 200 & 3.00 & 0.05 & 0.005 & 0.1 & 1 & 1 & 0 \\
\hline 6,7 & 250 & 100 & 5 & 500 & 6.00 & 0.05 & 0.005 & 0.1 & 1 & 1 & 0 \\
\hline $8 \mathrm{a}$ & 300 & 100 & 5 & 500 & 2.45 & 0.1 & 0.01 & 35 & 0.3 & 0.7 & 0 \\
\hline $8 \mathrm{~b}$ & 300 & 100 & 5 & 500 & 1.18 & 0.2 & 0.02 & 70 & 0.3 & 0.7 & 0 \\
\hline $8 \mathrm{c}$ & 300 & 100 & 10 & 500 & 3.05 & 0.1 & 0.02 & 23 & 0.3 & 0.7 & 0 \\
\hline $9 \mathrm{a}$ & 200 & 100 & 5 & 500 & 3.00 & 0.01 & 0.005 & 0.1 & 1 & 1 & 0 \\
\hline $9 \mathrm{~b}$ & 200 & 100 & 5 & 500 & 3.00 & 0.05 & 0.005 & 0.1 & 1 & 1 & 0 \\
\hline $9 \mathrm{c}$ & 200 & 100 & 5 & 500 & 3.00 & 0.1 & 0.005 & 0.1 & 1 & 1 & 0 \\
\hline 10,11 & $300-600$ & 100 & 5 & 500 & $\leq 3$ & 0.1 & $0.005-0.02$ & $15-200$ & 0.3 & 0.7 & 0 \\
\hline 12 & 300 & 100 & 5 & 500 & $\leq 3$ & 0.1 & 0.013 & $40,60,107,151$ & 0.3 & 0.7 & 0 \\
\hline 13 & $300-600$ & 100 & 5 & 500 & $\leq 4$ & 0.1 & 0.013 & 70 & 0.3 & 0.7 & $0-7.4$ \\
\hline
\end{tabular}

combinations of $D, K, E$, and $\ell$ that yield the same values of $D^{\prime}$ and $K^{\prime}$. For each of the three combinations, we performed ten model runs starting from different initial conditions, measured the mean valley spacing, and compared it with the valley spacing predicted by the other two combinations.

\subsection{Influence of Competition Between Advection and Diffusion}

[41] The relative magnitudes of the diffusion and advection terms in equation (13) reflect the transition in process dominance from hillslopes to valleys described by Davis [1892] and Gilbert [1909] and explored by numerous subsequent studies. To understand how this transition affects the valley spacing, we computed solutions for a range of $D^{\prime}$ and $K^{\prime}$ values, while holding $\theta^{\prime}=0$.

\subsection{Influence of Erosion Threshold}

[42] To explore the hypothesis that the spacing of valleys is controlled by a threshold for stream incision, we conducted a set of runs in which $\theta^{\prime}$ was varied while holding $D^{\prime}$ and $K^{\prime}$ constant.

\subsection{Parameters and Measurements}

[43] The parameters used to obtain all model solutions are listed in Table 1. With the exception of the time-dependent behavior discussed in section 5.1, all reported results are steady state solutions $(\partial z / \partial t=0$ for all $(x, y))$.

[44] We measured the relief, $\zeta$, in each model solution as the mean elevation along the topographic divide that parallels the $y$ boundaries (Figure 4). We measured the valley spacing in each solution with the spectral method described by Perron et al. [2008]. This method, which is similar to that used by Smith et al. [1997b] to measure rill spacing in their model, avoids the use of a potentially arbitrary criterion, such as a drainage area threshold, to define a channel network. Instead, it provides a measure of the dominant periodic component of the topography, which in this study corresponds to the ridge-valley structure in the $x$ direction. Two modifications to the spectral technique were made for the purpose of analyzing the model solutions. First, the surface used to detrend the model topography prior to taking the Fourier transform was constructed by averaging the elevations in the $x$ direction rather than by fitting a plane. Second, no windowing was performed because the model topography is periodic at the $x$ boundaries and tapers to zero at the $y$ boundaries. In cases where there were multiple spectral peaks, the frequency corresponding to the ridge-valley wavelength was calculated as the average of the peak frequencies, weighted by the spectral power of the peaks.

[45] The periodic boundary condition in the $x$ direction constrains the number of valleys on either side of the divide to be an integer, and thus the modeled valley spacing is "quantized" to some extent. To reduce this effect, we used grids with $N_{x} / N_{y} \geq 2$ in all cases, and $N_{x} / N_{y} \geq 3$ in most cases where our goal was to identify variations in $\lambda$.

\section{Results}

\subsection{Time-Dependent Behavior}

[46] The time evolution of the model topography provides some insight into the mechanisms by which quasiperiodic ridges and valleys develop. Figure 6 shows snapshots of the evolving topography over the course of a model run. As the rough, approximately planar initial surface $(t=0)$ is uplifted relative to the second-order streams at the $y$ boundaries, incipient valleys propagate from the $y$ boundaries into the interior of the grid $(t=$ $0.25 \mathrm{Ma}$ ). The relief of the landscape increases, and the centerline of the grid in the $y$ direction becomes a drainage divide, with the valleys on either side generally draining toward the nearest point on the $y$ boundary. The spacing between these incipient valleys is narrow on average, and relatively aperiodic. Valleys that initially capture larger drainage areas (and therefore have larger water discharge) incise vertically and propagate headward more rapidly than neighboring valleys with smaller drainage areas $(t=0.5-$ 1.4 Ma). This has two effects: first, it creates a positive feedback that results in the rapid capture of most of the drainage area by a few valleys that initially have larger drainage areas, thereby stunting the growth of valleys that begin with smaller drainage areas. Second, it creates steeper side slopes in the rapidly incising valleys, and because both the magnitude of the advective erosion term (equation (12)) and the creep flux (equation (3)) depend on the slope, the intervening ridgelines migrate toward the smaller valleys. Many of the small valleys subject to this competition disappear entirely $(t=2.5 \mathrm{Ma})$. If this elimination of small valleys proceeds to the point at which the spacing between the remaining valleys is too wide, however, new incisions form on the broad intervening ridges and propagate into the interior. From this competition between adjacent valleys, a stable configuration with uniformly spaced valleys eventually emerges $(t=4.0-6.0 \mathrm{Ma})$, and the topography con- 


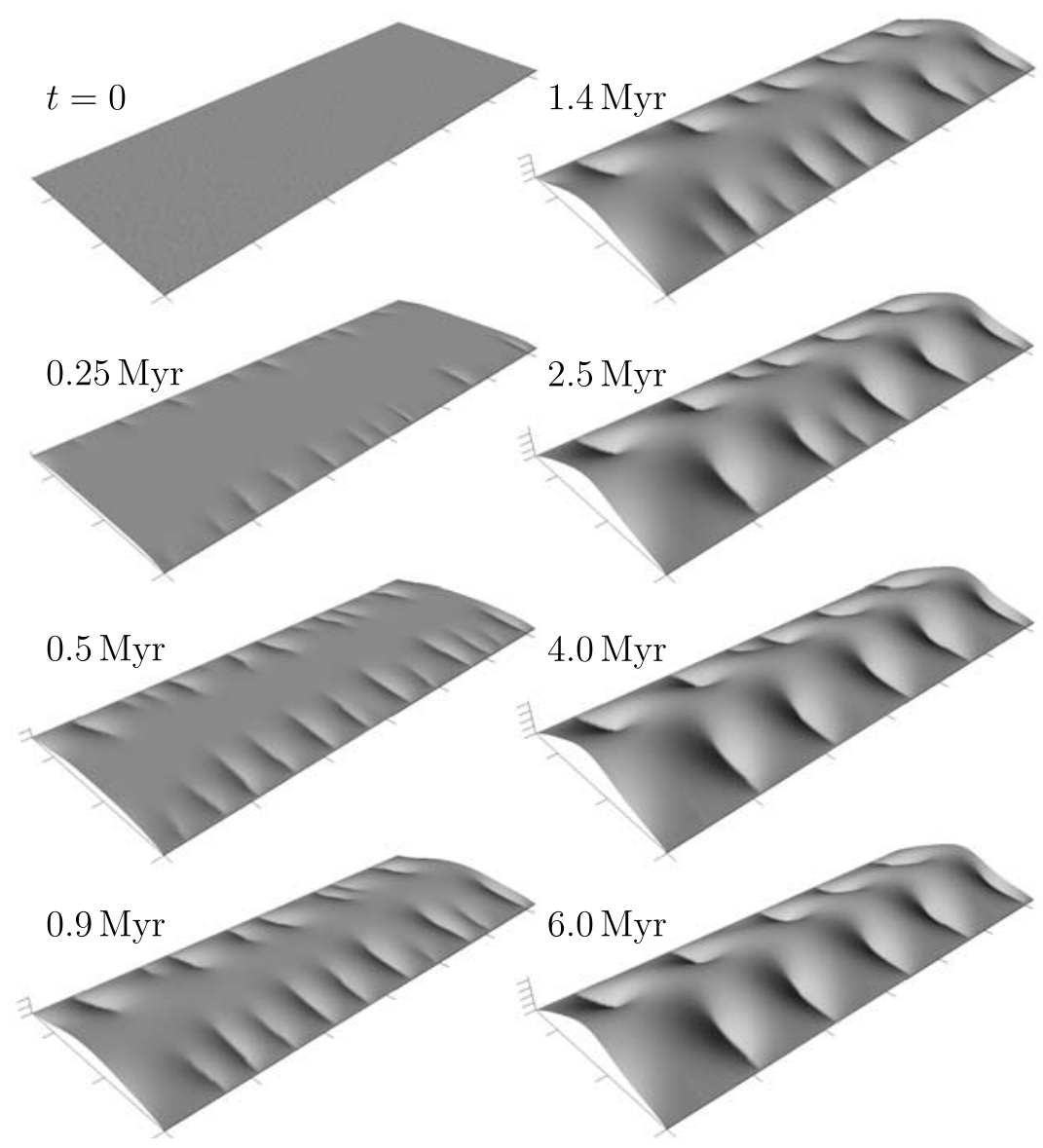

Figure 6. Evolution of the model topography at intervals spaced roughly logarithmically in time. Horizontal tick interval is $200 \mathrm{~m}$, vertical tick interval is $20 \mathrm{~m}$. No vertical exaggeration.

verges toward an equilibrium state $(\partial z / \partial t=0)$ in which the landscape no longer changes with time.

[47] We tracked the dimensionless relief, $\zeta^{\prime}$, and valley spacing, $\lambda^{\prime}$, through time (Figure 7 ). $\zeta^{\prime}$ increases monotonically throughout the simulation. Once the incipient valleys have propagated into the interior of the grid, $\zeta^{\prime}$ approaches its equilibrium value at a rate that declines roughly exponentially with time. The standard deviation of relief increases in proportion to the relief, but is very small throughout the simulation. $\lambda^{\prime}$ reaches a local minimum very early in the simulation as many incipient valleys form at the $y$ boundaries. The large standard deviation of $\lambda^{\prime}$ at this stage reflects the irregular spacing of the incipient valleys. $\lambda^{\prime}$ then increases monotonically as smaller valleys are forced out of existence by larger ones, and the standard deviation declines as the spacing of valleys becomes more uniform.

[48] Several aspects of this time-dependent behavior were anticipated conceptually by early studies of drainage networks. Gilbert [1877] noted the dependence of erosion rate on slope, and appealed to divide migration and lateral competition among streams as an explanation for the "great regularity" of badland drainage basins. He also described the expansion of basins at the expense of neighboring basins in a process he called "abstraction." His idealization of the geometry of badland divides [Gilbert, 1877, Figure 58] is very similar to the model domain used in this study. The competition between adjacent valleys for water was later proposed as a qualitative explanation for uniformly spaced rivers by Shaler [1899], who was understandably tempted to draw analogies to Darwin's [1859] theory of evolution by natural selection. Moreover, Shaler [1899] observed that the spacing of rivers is more uniform in more "evolved" landscapes, i.e., landscapes in which the cumulative eroded relief is greater. Our results support this observation, as the variance in valley spacing is smaller at equilibrium than it is

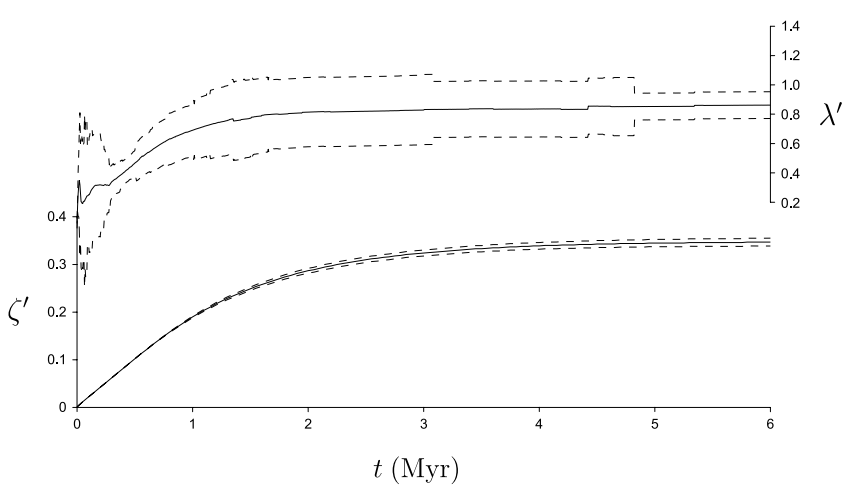

Figure 7. Time evolution of mean dimensionless valley spacing, $\lambda^{\prime}$, and mean dimensionless relief, $\zeta^{\prime}$, for the model run shown in Figure 6. Dashed lines are $1 \sigma$ envelopes. 


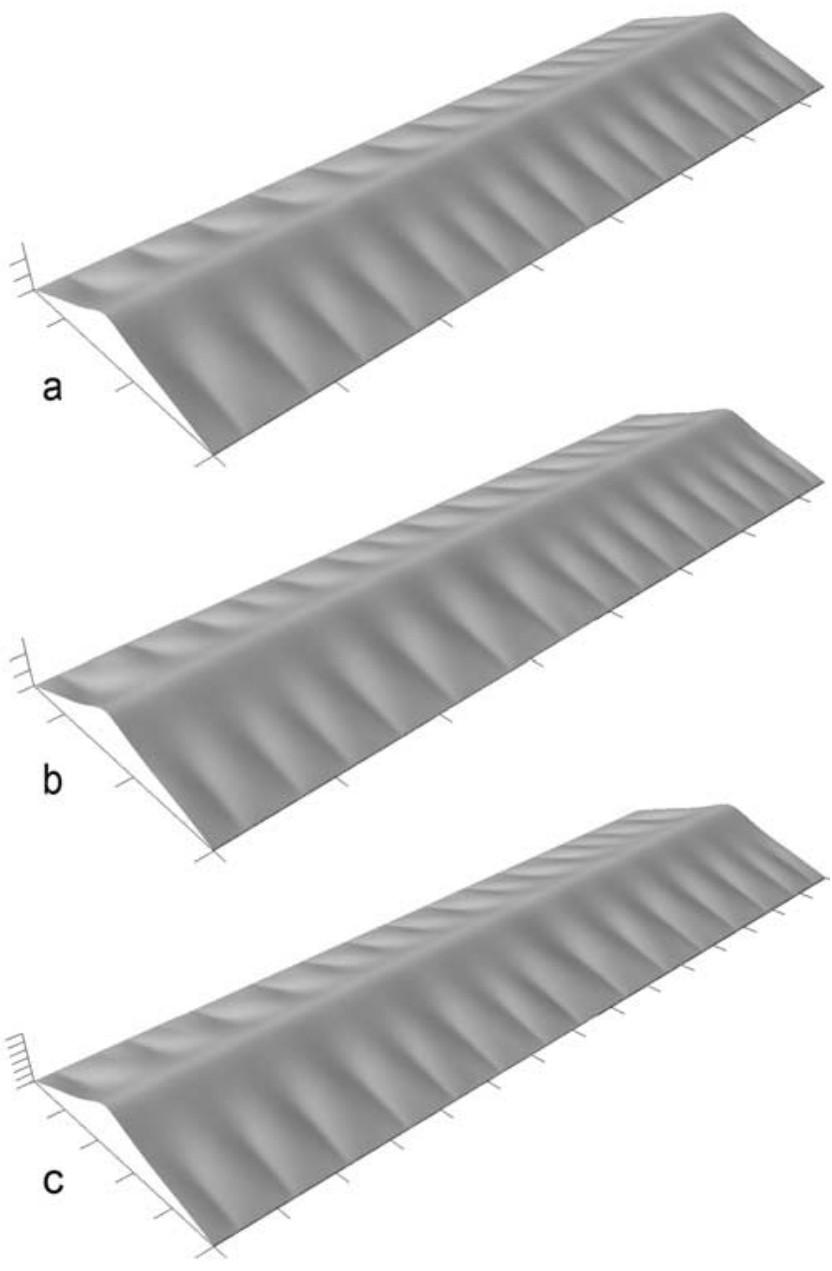

Figure 8. Equilibrium model solutions with different values of $D, K, \ell^{\prime}$, and $E$ but the same values of the dimensionless diffusivity, $D^{\prime}$, and dimensionless stream incision coefficient, $K^{\prime}$. (a) Reference parameters. (b) $D, K$, and $E$ are twice as large as in Figure 8a. (c) The parameter $\ell$ is twice as large as in Figures 8a and 8b. Parameter values are listed in Table 1. Horizontal tick interval is $200 \mathrm{~m}$; vertical tick interval is $10 \mathrm{~m}$. Vertical exaggeration $3 \mathrm{X}$.

in the transient state (Figure 7). Horton [1945] also recognized the importance of the competition for drainage area in developing networks. The dominance of erosional features that initially capture more drainage is one of the main principles in his model for the evolution of rill networks, and the growth of these basins at the expense of smaller neighboring ones is similar in some respects to his description of basin growth by cross-grading.

\subsection{Validation of Dimensionless Quantities}

[49] Figure 8 shows three model solutions with unique combinations of $D, K, \ell$, and $E$ values, but the same dimensionless diffusivity, $D^{\prime}$, and dimensionless stream incision coefficient, $K^{\prime}$. The means and standard errors from 10 model runs for the cases in Figures $8 \mathrm{a}-8 \mathrm{c}$ are $\lambda^{\prime}=$ $0.432 \pm 0.012, \zeta^{\prime}=0.120 \pm 0.00002$ (Figure 8a); $\lambda^{\prime}=0.421 \pm$ $0.004, \zeta^{\prime}=0.120 \pm 0.00002$ (Figure 8b); and $\lambda^{\prime}=0.437 \pm$ $0.007, \zeta^{\prime}=0.120 \pm 0.00003$ (Figure 8c). The fact that these predicted values are within two standard errors of one another, despite differences of a factor of 2 or more in process rates and spatial scales (Table 1), indicate that $D^{\prime}$ and $K^{\prime}$ are good predictors of the basic characteristics of the model topography, and that our choices of the characteristic length scales $\ell$ and $\zeta$ (Figure 4) are appropriate. In sections 5.3 and 5.4, we show that some of these topographic characteristics, including valley spacing, are sensitive only to Pe.

[50] The dependence of $\mathrm{Pe}$ on $\zeta$, but not on $E$, suggests that the driving erosion rate may only control the valley spacing through its influence on relief, provided equation (13) is valid for the erosion rates considered. In addition, equation (21) implies that $\mathrm{Pe}$ is independent of relief if the kinematic wave term in equation (13) is linear in $|\nabla z|$ (i.e., $n=1$ ) and $\theta_{c}=0$.

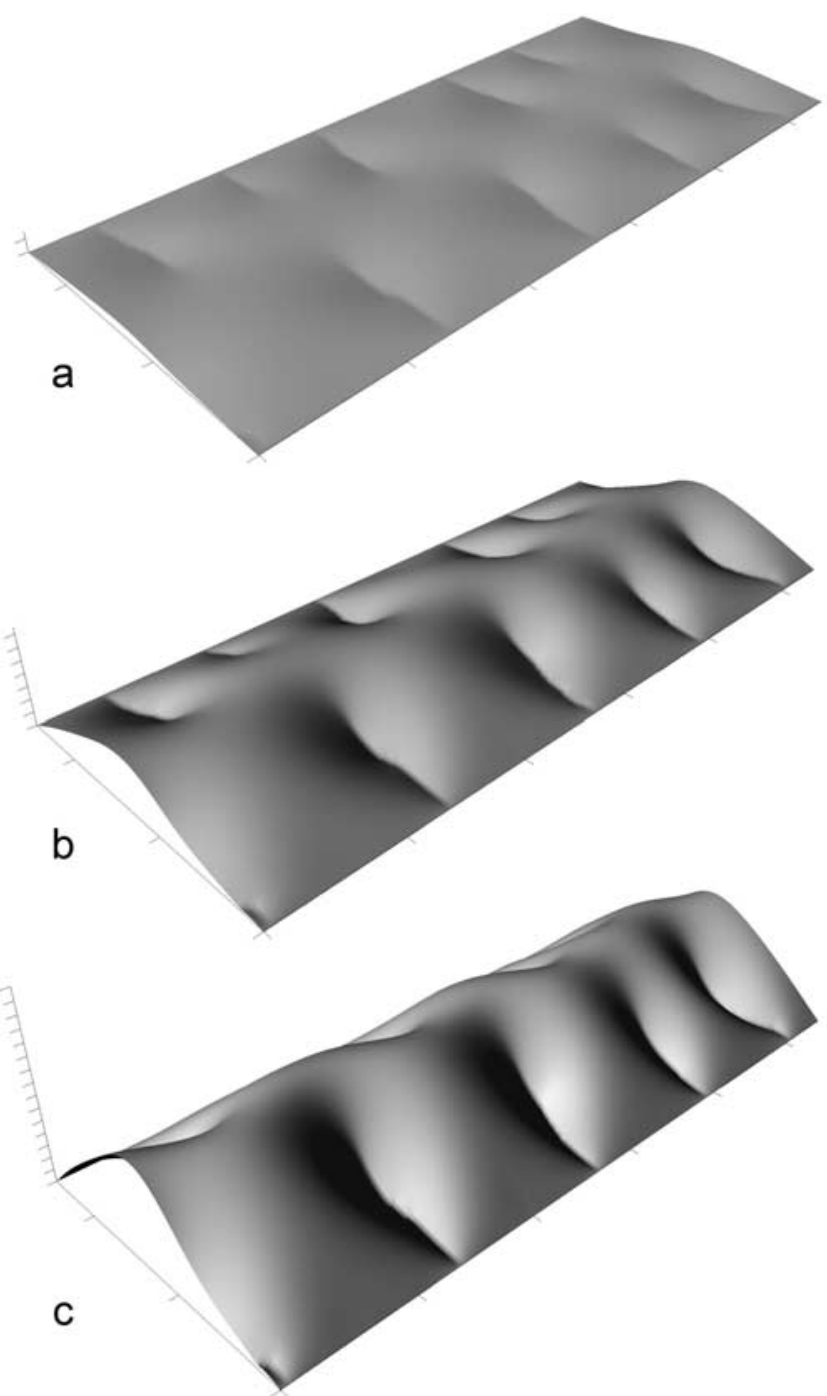

Figure 9. Equilibrium model solutions for $m, n=1$ and driving erosion rates $(E)$ spanning an order of magnitude: (a) $E=0.01 \mathrm{~mm} \mathrm{a}^{-1}$, (b) $E=0.05 \mathrm{~mm} \mathrm{a}^{-1}$, and (c) $E=$ $0.1 \mathrm{~mm} \mathrm{a}^{-1}$. All three runs used the same initial condition. The $x$ boundaries have been extended periodically to better display features that span the boundaries. Horizontal tick interval is $200 \mathrm{~m}$, vertical tick interval is $20 \mathrm{~m}$. No vertical exaggeration. 

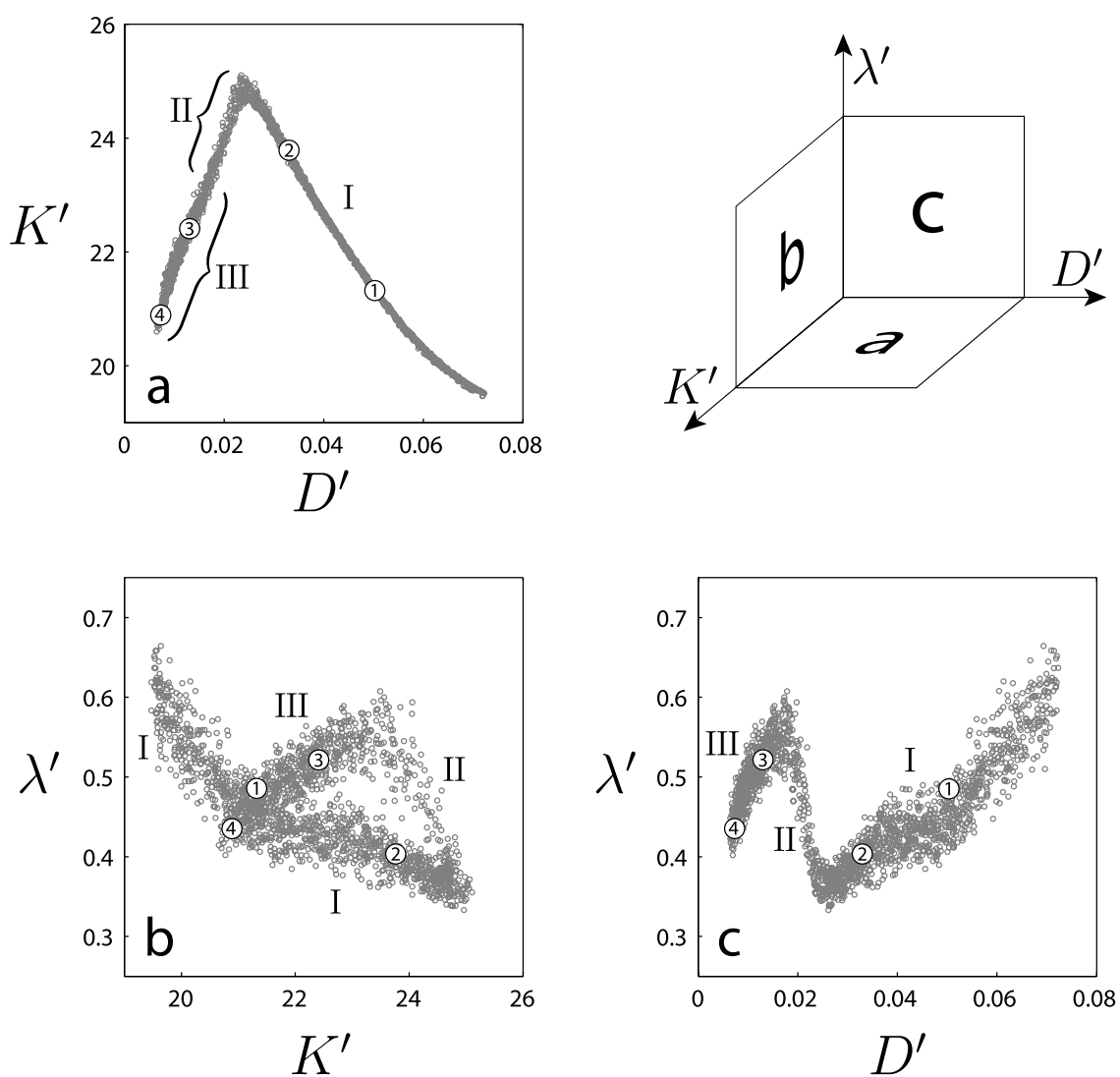

Figure 10. Plots of model solutions in the three-space defined by $\left(D^{\prime}, K^{\prime}, \lambda^{\prime}\right)$ projected onto three orthogonal planes, as indicated in the inset. Each point represents the mean valley spacing and relief of a single solution. Trends labeled I-III correspond to the three scaling regimes discussed in section 5.3. Symbols labeled 1-4 correspond to the representative solutions shown in Figure 12.

This prediction is consistent with the findings of Howard [1997] and Tucker and Bras [1998] that erosion rate has no effect on drainage density if $n=1$ and $\theta_{c}=0$, and it is borne out by our numerical experiments. Setting $n=1$ and $\theta_{c}=0$ and varying the erosion rate leads to dramatic variations in relief, but no change in valley spacing (Figure 9). If the same initial conditions are used, the positions of the valleys are identical; only the vertical dimension of the landscape changes. However, we find that for $n \neq 1$ or $\theta_{c}>0$, both the relief and the position and spacing of the valleys depend on $E$.

\subsection{Influence of Competition Between Advection and Diffusion}

[51] By analyzing the equilibrium topography of model solutions for a range of $D^{\prime}$ and $K^{\prime}$, with $m, n \neq 1$ and $\theta^{\prime}=0$, we identified scaling relationships for dimensionless valley spacing and relief in landscapes that are shaped by competing advective and diffusive processes. These scaling relationships, which are presented graphically in Figure 10, consist of a set of linear trends in the three-space defined by $D^{\prime}, K^{\prime}$, and $\lambda^{\prime}$, each of which can be described by the set of parametric equations:

$$
\left[\begin{array}{l}
K^{\prime} \\
D^{\prime} \\
\lambda^{\prime}
\end{array}\right]=\boldsymbol{\alpha} s+\boldsymbol{\beta},
$$

where $\boldsymbol{\alpha}$ and $\boldsymbol{\beta}$ are vectors of constants and $s$ is a parameter that defines the range over which the relationship applies.

[52] The same trends can be visualized somewhat more simply as a plot of $\lambda^{\prime}$ against Pe or its inverse (a projection of the data in Figure 10 onto a plane parallel to the $\lambda^{\prime}$ axis), as in Figure 11. To illustrate the changes in the topography that correspond to the scaling trends, representative model solutions are shown in Figure 12, and the corresponding locations in parameter space are indicated in Figures 10 and 11 .

[53] Several distinct scaling regimes are evident. For small Pe, the region marked "no valleys" in Figure 11, valleys are not easily distinguishable, and the model solution resembles a steep, undissected ridgeline. Thus, $\lambda^{\prime}$ is not plotted in this region of Figure 11. In steep landscapes, slope failures and debris flows are likely to occur, and these processes can play a role similar to that of stream incision. Field studies have shown that debris flows can incise entire valley networks in which fluvial wear is minor [Seidl and Dietrich, 1992; Howard, 1998; Sklar and Dietrich, 1998; Stock et al., 2005; Stock and Dietrich, 2003, 2006]. Thus, when Pe is small, there are two possible results. If the small $\mathrm{Pe}$ reflects a low value of $K$ relative to $D$, the landscape will steepen to the point that valley-forming erosion processes not included in our model will become effective. If, on the other hand, the 

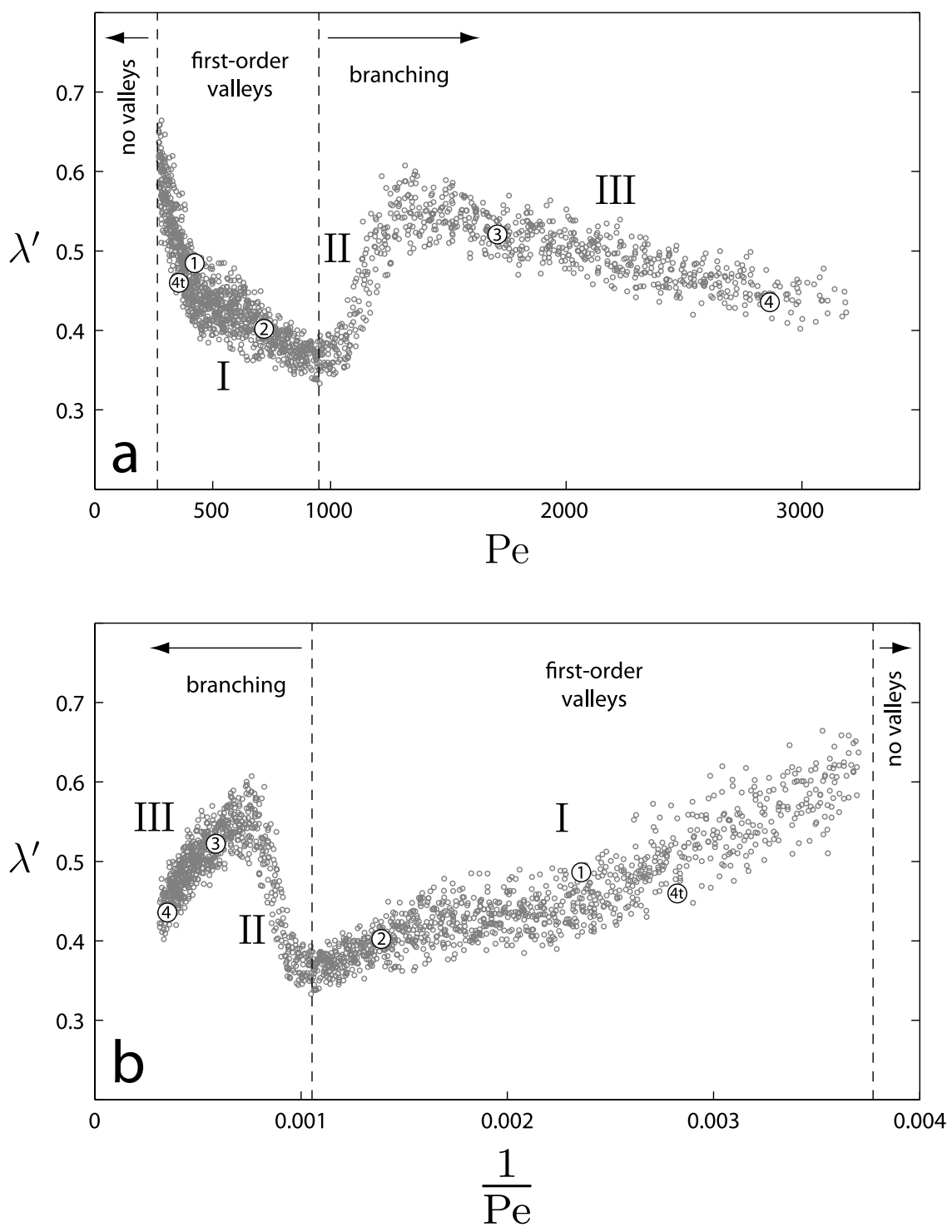

Figure 11. Same data as in Figure 10 plotted against (a) Pe and (b) its inverse. As in Figure 10, trends labeled I-III correspond to the three scaling regimes discussed in section 5.3, and symbols labeled 1-4 correspond to the representative solutions shown in Figure 12. Symbols labeled 4t correspond to the firstorder tributary basins in solution 4 from Figure 12.

small Pe reflects a small $\ell$ value (i.e., if the spatial scale of the landscape is small), an undissected hillslope will form.

[54] At intermediate values of Pe, first-order valleys form, and we observe the hypothesized narrowing of valley spacing as Pe increases. This trend, labeled regime $\mathrm{I}$ in Figures 10 and 11, is illustrated by the difference between the model solutions labeled 1 and 2 in Figure 12. $\lambda^{\prime}$ varies linearly with $\mathrm{Pe}^{-1}$ in regime I (Figure $11 \mathrm{~b}$ ).

[55] As Pe increases beyond regime I, the valley spacing reaches a minimum, and then begins to increase. This occurs because the valleys branch, forming tributaries (solution 3 in Figure 12), and the incision of these tributaries on either side of the ridgelines that run perpendicular to the $y$ boundaries widens the second-order basins. This trend of increasing valley spacing due to branching is labeled regime II in Figures 10 and 11. Figure 11b shows that $\lambda^{\prime}$ for the second-order, branching basins varies linearly with $\mathrm{Pe}^{-1}$ in regime II. Note from the definition of Pe in equation (21) that for $n<2 m+2$, the increase in Pe that leads to branching can be thought of as either an increase in $K / D$ or an increase in $\ell$. That is, an increase in the ratio of stream incision to diffusive transport that causes branching is equivalent to viewing a landscape at a larger spatial scale. Conversely, smaller spatial scales correspond to smaller Pe. For example, if $\ell$ and $\zeta$ are taken to be the length and relief of the tributary basins in the branching model solution labeled 4 in Figure 12, the resulting value of Pe falls within regime I (points labeled 4t in Figure 11), which reinforces the conclusion that this is the range of Pe that corresponds to first-order basins, independent of their size.

[56] At still higher values of Pe, the sign of the scaling trend is again reversed: branching valleys become more narrowly spaced, as illustrated by the difference between model solutions 3 and 4 in Figure 12. This trend in the 


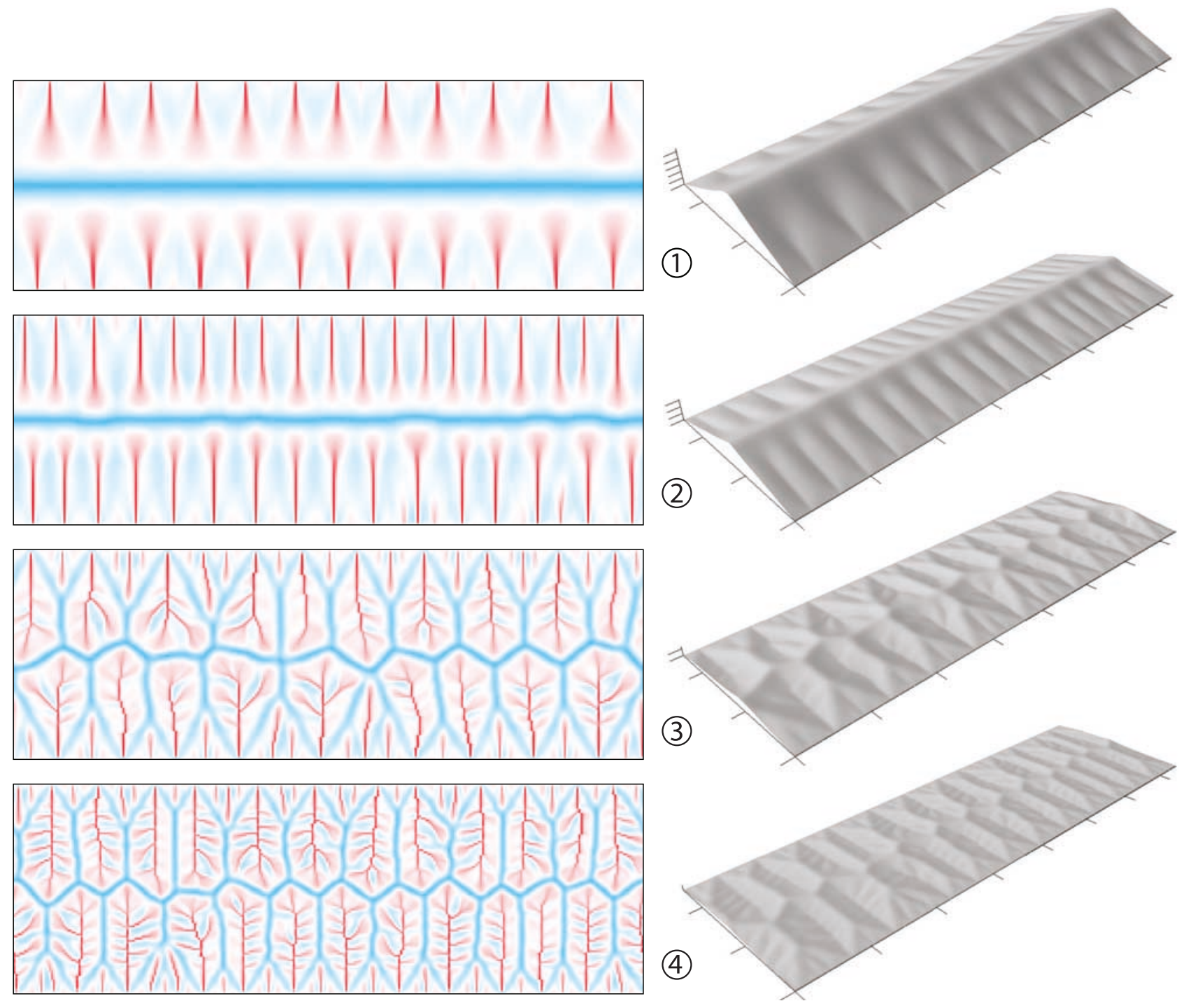

Figure 12. Four representative solutions to equation (13) showing the variety of observed behavior. Locations of the solutions are indicated on the scaling plots in Figures 10 and 11. Colors in the image maps (left) show the Laplacian of elevation $\left(\nabla^{2} z\right)$ normalized to the maximum and minimum values in the grid. Concave-up areas (red) are valleys; concave-down areas (blue) are hillslopes. Axis tick intervals in the perspective views (right) are $200 \mathrm{~m}$ in the horizontal and $5 \mathrm{~m}$ in the vertical. Vertical exaggeration $4 \mathrm{X}$.

spacing of second-order basins, labeled regime III in Figures 10 and 11, is analogous to that observed in firstorder basins in regime I, except that $\lambda^{\prime}$ varies linearly with $\mathrm{Pe}$ in regime III (Figure 11a). The observed trends with Pe make intuitive sense: valley spacing scales linearly with $K$ (and therefore $\mathrm{Pe}$ ) in advection-dominated landscapes, such as branching basins, and linearly with $D$ (and therefore $\mathrm{Pe}^{-1}$ ) in diffusion-dominated landscapes, such as first-order basins.

[57] The trends in Figures 10 and 11 imply that transitions in structure among drainage basins can be abrupt even in the absence of thresholds in the governing equations. It is possible that transitions in natural basins are more gradual because they are not constrained by boundary conditions with a fixed geometry. For example, differences in Pe that affect the geometry of natural first-order basins would presumably also affect the structure of higher-order basins, whereas the $y$ dimension of our model grids, which represents the spacing between two higher-order streams, remains fixed. But transitions among natural basins could be still abrupt insofar as the boundary conditions we have chosen mimic situations that do sometimes occur in real basins, such as a transient response to a change in Pe in which low-order basins respond faster than the higher-order basins that contain them. One way to resolve this issue would be to model the development of higher-order drainage basins in which the interior, nested basins are not strongly affected by boundary conditions.

[58] The relief, $\zeta$, does not undergo abrupt changes in behavior, but rather declines monotonically as Pe increases, 
Table 2. Parameter Values for Scaling Relationships in Equations (22), (27), and (28)

\begin{tabular}{|c|c|c|c|c|c|c|}
\hline Scaling Regime $^{\mathrm{a}}$ & $\alpha$ & $\boldsymbol{\beta}$ & $s$ & $\gamma_{1}$ & $\gamma_{2}$ & $\mathrm{Pe}$ \\
\hline I & {$\left[\begin{array}{c}-1.000 \\
0.007 \\
0.025\end{array}\right]$} & {$\left[\begin{array}{c}22.600 \\
0.041 \\
0.424\end{array}\right]$} & $-2.27-1.89$ & $59 \pm 2$ & $0.32 \pm 0.003$ & $270-950$ \\
\hline II & {$\left[\begin{array}{c}0.993 \\
0.003 \\
-0.117\end{array}\right]$} & {$\left[\begin{array}{c}24.325 \\
0.021 \\
0.460\end{array}\right]$} & $-0.93-1.03$ & $-1084 \pm 78$ & $1.41 \pm 0.07$ & $950-1350$ \\
\hline III & {$\left[\begin{array}{l}0.999 \\
0.004 \\
0.046\end{array}\right]$} & {$\left[\begin{array}{c}22.014 \\
0.011 \\
0.502\end{array}\right]$} & $-1.31-1.69$ & $-6.94 \pm 0.17 \times 10^{-5}$ & $0.64 \pm 0.004$ & $>1350$ \\
\hline
\end{tabular}

${ }^{\mathrm{a}}$ See section 5.3 for definitions.

as shown by the perspective views of the topography in Figure 12. It is possible to predict $\zeta$ from process rates and boundary conditions using the scaling relationship identified above. Equation (22) can be rewritten as

$$
\frac{K^{\prime}-\beta_{1}}{\alpha_{1}}=\frac{D^{\prime}-\beta_{2}}{\alpha_{2}}=\frac{\lambda^{\prime}-\beta_{3}}{\alpha_{3}}=s,
$$

where $\alpha_{n}$ and $\beta_{n}$ are the components of $\boldsymbol{\alpha}$ and $\boldsymbol{\beta}$. Combining the first two terms of equation (23) and using the definitions of $K^{\prime}$ and $D^{\prime}$ from equation (19) yields an implicit expression for $\zeta$ that can be solved iteratively:

$$
\zeta=\frac{E \ell^{2}}{D}\left[\beta_{2}+\frac{\alpha_{2}}{\alpha_{1}}\left(\frac{K \ell^{2 m-n} \zeta^{n}}{E}-\beta_{1}\right)\right] .
$$

This calibrated expression for total drainage basin relief complements fully analytic expressions for hillslope or fluvial relief alone [Whipple and Tucker, 1999; Roering et al., 2007] and expressions for total relief based on simplified hillslope process laws [Tucker and Whipple, 2002].

[59] Once relief is known, the dimensionless valley spacing, $\lambda^{\prime}$, can be predicted either by combining the first and third terms of equation (23), yielding an expression that is independent of $D$,

$$
\lambda^{\prime}=\beta_{3}+\frac{\alpha_{3}}{\alpha_{1}}\left(\frac{K \ell^{2 m-n} \zeta^{n}}{E}-\beta_{1}\right),
$$

or by combining the second and third terms, yielding an expression that is independent of $K$,

$$
\lambda^{\prime}=\beta_{3}+\frac{\alpha_{3}}{\alpha_{2}}\left(\frac{D \zeta}{E \ell^{2}}-\beta_{2}\right) .
$$

The values of $\boldsymbol{\alpha}, \boldsymbol{\beta}$ and $s$ corresponding to the three scaling regimes, which were determined by orthogonal linear regression from the data in Figure 10, are given in Table 2, along with the range of $\mathrm{Pe}$ that defines each regime.

[60] As Figure 11 suggests, $\lambda^{\prime}$ can also be found in terms of Pe. The linear trends for regimes I and II have the form

$$
\lambda^{\prime}=\frac{\gamma_{1}}{\mathrm{Pe}}+\gamma_{2},
$$

and the linear trend for regime III has the form

$$
\lambda^{\prime}=\gamma_{1} \mathrm{Pe}+\gamma_{2},
$$

where $\gamma_{n}$ are constants whose values are listed in Table 2 .

\subsection{Influence of Erosion Threshold}

[61] As mentioned in section 3, a nonzero stream incision threshold, $\theta_{c}$, affects the governing equation in two ways. First, it is subtracted from the advection term, and therefore reduces Pe (equation (20)). This is similar to the effect discussed in section 5.3, and it should widen valley spacing in the same sense as a reduction in $K$. Several previous studies have obtained the analogous result that there is a positive relationship between the magnitude of an erosion threshold and valley head source area [e.g., Kirkby, 1994; Howard, 1994a, 1997; Tucker and Bras, 1998].

[62] Second, a nonzero stream incision threshold will reduce the landscape area over which the advection term acts, as expressed by the piecewise function in equation (5). This is the "critical distance" effect proposed by Horton [1945] to explain the finite extent of landscape dissection by stream networks. One might expect the absence of stream incision on ridgelines and divides (or, for large $\theta_{c}$, on hillslopes in general) to produce an additional widening of valley spacing beyond that predicted by the reduction in Pe.

[63] Figure 13 shows that this is not necessarily the case. Increasing $\theta_{c}$ from zero to $7.4 \mathrm{~m}^{0.6}$ (the range over which

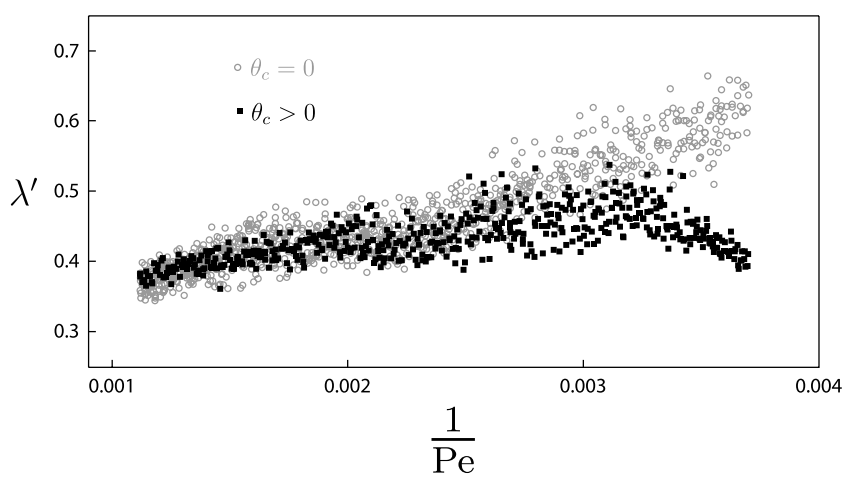

Figure 13. Effect of a variable stream incision threshold on dimensionless valley spacing. Open gray circles are the model solutions for regime I (first-order basins) in Figure 11. Black squares are solutions with a nonzero threshold. Pe is calculated with equation (20). 


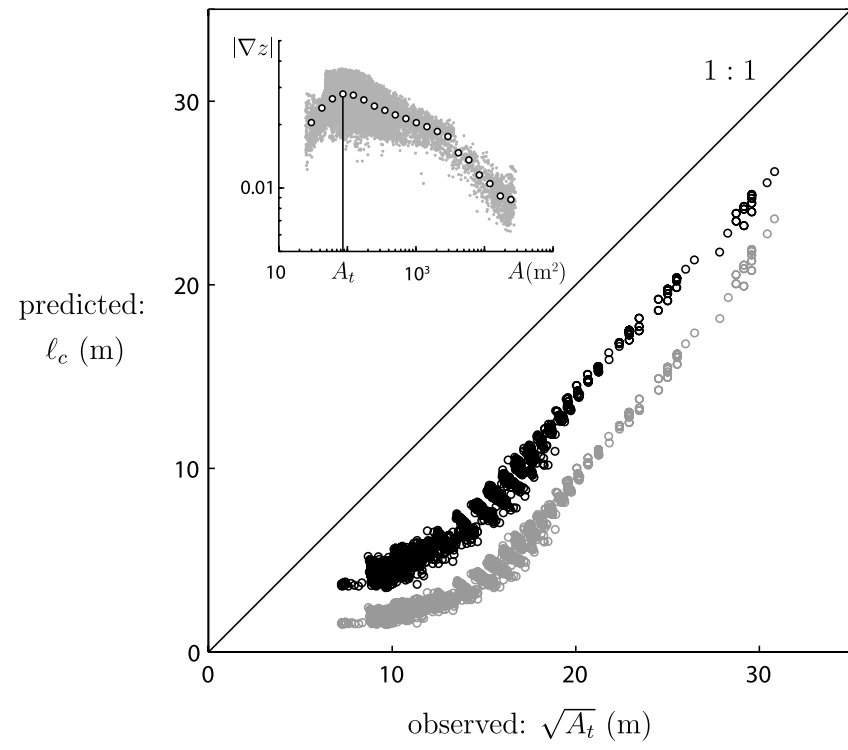

Figure 14. Predicted length scale of the hillslope-valley transition, $\ell_{c}$, compared with the observed length scale at which the slope-area curve reaches a maximum, $\sqrt{A_{t}}$, for model solutions in Figures 10 and 11. Black symbols are predictions obtained by assuming equal advection and diffusion timescales at the hillslope-valley transition (equation (29)). Gray circles are predictions obtained by assuming that the advective and diffusive terms acting independently would produce the same slope and erosion rate (equation (30)). The inset shows the definition of $A_{t}$ on a slope-area plot for an individual model solution.

stable first-order valleys form) while holding all other parameters constant produces a large increase in relief and causes valley heads to form farther from the central divide [Tucker and Bras, 1998], but the accompanying increase in valley spacing is no greater than that predicted by the reduction in Pe. At high values of $\theta_{c}$, the sign of the relationship between valley spacing and $\theta_{c}$ even becomes negative. Relief increases because the threshold limits the effectiveness of the stream incision term for a given drainage area and slope, forcing the landscape to steepen in order to erode at a rate equal to the driving surface uplift rate, $E$. This increased steepness partly compensates for the effect of the threshold, leading to a decrease in Pe that is modest relative to the size of the increase in $\theta_{c}$. For the case shown in Figure 13, for example, increasing $\theta_{c}$ from 1 to $6 \mathrm{~m}^{0.6}$ causes Pe to shrink by less than a factor of 2 .

[64] It is important to note, however, that if the erosion threshold steepens the landscape to the point that processes not included in equation (13) become important, the effect on valley spacing could be more pronounced, and the scaling relationships derived here may no longer apply. In particular, steeper slopes could cause the nonlinear dependence of creep flux on slope to become important [Roering et al., 1999], or trigger landsliding and debris flows. A detailed treatment of these processes is beyond the scope of this study, but it seems likely that their effect on valley spacing would be significant.

[65] In addition to its control on relief, the "critical distance" effect has a significant influence on subtler characteristics of the topography, such as the shapes of hillslope and valley-head profiles. For example, restricting the action of the advective term to valley bottoms leads to the formation of more uniformly curved hillslopes [e.g., Howard, 1994a; Tucker and Bras, 1998].

\section{Discussion}

[66] We have focused primarily on how the relative rates of the dominant erosion processes control quasiperiodic valley spacing, but it seems likely that this competition also controls other characteristic dimensions of the topography that reflect the interaction of hillslope and fluvial processes, such as the scale at which hillslopes transition into valleys. As mentioned in section 1, a widely recognized signature of this transition is a peak in a plot of topographic slope, $|\nabla z|$, against contributing area, $A$ (Figure 14 inset) [e.g., Tarboton et al., 1989, 1992; Willgoose et al., 1991d, 1992; Willgoose, 1994b; Howard, 1994a]. The contributing area at which this peak in slope occurs, $A_{t}$, is thought to mark the scale at which fluvial erosion begins to outpace erosion by hillslope processes [Willgoose et al., 1991d; Willgoose, 1994b; Howard, 1994a, 1997; Moglen et al., 1998; Tucker and Bras, 1998; Dietrich et al., 2003]. We find support for this idea in a simple scaling argument. The ratio of advection and diffusion timescales reflects the relative magnitudes of processes that form valleys and those that inhibit valley formation. This ratio is scale-dependent; that is, $\mathrm{Pe}$ is a function of $\ell$. We can therefore solve equation (21) for the characteristic length for which these timescales are equal $(\mathrm{Pe}=1)$ :

$$
\ell_{c}=\left(\frac{D}{K} \zeta^{1-n}\right)^{\frac{1}{2(m+1)-n}} .
$$

Following Willgoose et al. [1992], we define the length scale associated with the observed slope-area transition as $\sqrt{A_{t}}$. We find that $\ell_{c}$ provides a good estimate of $\sqrt{A_{t}}$ for the numerical solutions presented earlier, underestimating $\sqrt{A_{t}}$ by a factor of 1.1 to 3.1, and by less than a factor of 2 in most cases (Figure 14).

[67] This approach differs from that of Howard [1994a, 1997], who estimates $A_{t}$ as the contributing area for which the hillslope and fluvial erosion terms independently give the same equilibrium slope and erosion rate. A similar approach has been used for transport-limited conditions by Willgoose et al. [1991d], Moglen et al. [1998] and Tucker and Bras [1998], who estimate $A_{t}$ as the contributing area for which the hillslope and fluvial terms contribute equally to the total sediment flux. This approach predicts (compare equation (13) of Howard [1997])

$$
\ell_{c}=\left[\frac{D^{n}}{K}\left(\frac{E}{2}\right)^{1-n}\right]^{\frac{1}{m+n}},
$$

which underestimates $\sqrt{A_{t}}$ by a factor of 1.3 to 7.3 (Figure 14). Equation (29) has the disadvantage that it requires knowledge of the relief, but this may also be the reason why it performs slightly better than equation (30), which accounts for the vertical dimension of the topography 
indirectly via the dependence on $E$. Another possible reason for the discrepancy is that equation (30) is derived from a one-dimensional analysis that neglects the effects of topographic convergence on the hillslope-valley transition. The two expressions predict a similar dependence of $\ell_{c}$ on $D$ and $K$, but the differing exponents suggest that their relative performance over a wide range of parameter values is a topic worthy of further investigation.

[68] The characteristic length $\ell_{c}$ also provides a framework for estimating the spatial scale of first-order drainage basins. As shown in Figure 11, valleys do not form when $\mathrm{Pe}<270$. From equations (21) and (29), this implies $\ell / \ell_{c}<$ $270^{1 /(2(m+1)-n)} \approx 19$. Thus, stable valleys will form only if the length of a slope exceeds the characteristic length by roughly an order of magnitude or more. Shorter slopes will remain undissected. Because $\ell_{c}$ is a function of $\zeta$, this criterion reflects the steepness of the slope as well as its length.

[69] The qualitative changes in the model landscapes at the edges of the Pe range where first-order basins form (Figures 11 and 12) suggest an explanation for the restricted range of width-to-length ratios observed in first-order drainage basins in nature. Hack [1957] observed that drainage basins scale nearly self-similarly, such that the ratio of drainage area to $\ell^{2}$ is nearly scale-independent. Montgomery and Dietrich [1992, Figure 2] measured lengths and areas for a large number of basins ranging from unchanneled headwater catchments to major river systems, and found that the ratio of area to length (a rough measure of width) for basins of a given length varies only by a factor of a few. We observe a similarly narrow range of basin aspect ratios in our equilibrium model results. First-order basins, which form at intermediate $\mathrm{Pe}$, have $0.3 \leq \lambda^{\prime} \leq 0.9$ for the cases examined here. At smaller Pe, rather than becoming wider, valleys become so indistinct that the solution is essentially an undissected ridgeline, and the topography becomes so steep that stronger valley-forming processes, such as debris flows, should become active. At higher Pe, rather than becoming narrower, valleys branch, and are therefore no longer first-order. Thus, our simple model provides a possible explanation for the observation that aspect ratios of natural first-order basins do not deviate greatly from 1 .

[70] This result, like the other inferences derived from our numerical experiments, is not directly applicable to higherorder drainage basins, which far exceed the spatial scale at which creep processes are effective $\left(\ell \gg \ell_{c}\right)$. But high-order basins are composed of collections of smaller basins, and so it is possible that the scaling relationships presented here have implications for the structure and dimensions of drainage networks at scales much larger than first-order basins. The long times required to alter the structure of large basins is a significant factor (it has even been suggested that the regular basin spacing commonly observed in linear mountain fronts [Hovius, 1996; Talling et al., 1997] has been inherited from antecedent lowland drainage patterns [Castelltort and Simpson, 2006]), but the dynamics of small basins could nonetheless be important. More work is clearly required to understand the scaling and structure of large, high-order drainage basins in which erosion is dominated by fluvial processes.

[71] The model presented here is intended to describe a specific type of landscape, and our results, including the scaling relationships and the finding that variations in the relative rates of advective and diffusive processes have a stronger effect on valley spacing than variations in a stream incision threshold, may not apply to landscapes that are very different. Our model describes a landscape like the Gabilan Mesa (Figure 2): soil-mantled, with sufficient surface cohesion that fluvial incision is detachment-limited, and slopes gentle enough that nonlinear diffusion effects [Roering et al., 1999, 2007], slope failures, and debris flows do not contribute significantly to erosion. As previous modeling studies have noted, this is one of the simplest cases that leads to the formation of drainage basins [Howard, 1994a; Tucker and Bras, 1998]. We have investigated the dynamics of such a landscape in detail, while acknowledging the possibility that the form, and even the sign, of relationships between process rates and topographic characteristics can depend on the entire set of processes that are at work [Tucker and Bras, 1998; Talling and Sowter, 1999]. Our objective is not to identify these relationships for all possible suites of geomorphic processes, but to make a simple prediction, about a specific kind of landscape, that can be tested in the field.

[72] Efforts to model the long-term evolution of landscapes, including the present one, have shown that an equation with the form of equation (13) can generate solutions that resemble landscapes ranging from first-order drainage basins [e.g., Willgoose et al., 1991a; Howard, 1994a; Tucker and Bras, 1998] to entire orogens [e.g., Tucker and Slingerland, 1996; Kooi and Beaumont, 1996; van der Beek and Braun, 1998; Whipple and Tucker, 1999]. Despite the many insights that such studies have offered into the dynamics of evolving landforms, it remains somewhat unclear whether the model landscapes merely look realistic, or whether they accurately predict the form and dimensions of real topography. A common criticism of model equations that are similar in form to equation (13) is that some of their components, particularly the stream incision term, are based on descriptions of geomorphic processes that have not been adequately tested in the field. For example, the linear excess shear stress model (equation (5)) is a commonly used expression for which limited supporting evidence is available [Dietrich et al., 1993]. The scarcity of evidence is due in part to the gradual and often episodic nature of erosion processes, which makes direct field measurements difficult and hinders calibration efforts. It is therefore challenging to test the predictions of landscape evolution models by comparison with specific landscapes, yet this is exactly what is necessary to evaluate the adequacy of the equations on which the models are based [Willgoose, 1994a; Church, 2003; Dietrich et al., 2003; Hoey et al., 2003; Willgoose et al., 2003]. The first step should be to test a model's ability to reproduce the most salient topographic features that emerge in an evolving landscape. Uniform valley spacing is one such feature, and the scaling relationships presented here provide a framework for such a test.

\section{Conclusions}

[73] We investigated the development of evenly spaced first-order drainage basins using a simple numerical model that includes two processes: diffusion-like sediment trans- 
port due to creep or rain splash, and detachment-limited fluvial erosion. As the model topography evolves over time, evenly spaced basins develop through a competition for drainage area, in which basins that initially capture more area due to slight differences in initial conditions are able to stunt the growth of smaller adjacent basins. As the topography approaches an equilibrium, valley spacing becomes more regular through the disappearance of these smaller basins and through lateral migration of drainage divides and valleys.

[74] The most important parameter controlling landscape morphology in such a system is a dimensionless ratio of diffusion to advection timescales, which is analogous to a Péclet number, Pe. The length scales used to define Pe are the vertical relief and horizontal length of a drainage basin. At low values of Pe $\left(\lesssim 10^{2}\right)$, no drainage basins form. At

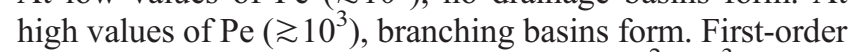
basins form at intermediate values of $\operatorname{Pe}\left(\sim 10^{2}-10^{3}\right)$, with a lateral spacing that varies linearly with $\mathrm{Pe}^{-1}$. The restricted range of spacings over this intermediate range of $\mathrm{Pe}$ suggests an explanation for the restricted range of widthto-length ratios observed in natural first-order basins. The transition from hillslope to valley morphology, as expressed by the peak in a plot of topographic slope against drainage area, occurs at a drainage area that gives $\mathrm{Pe} \approx 1$.

[75] Both the competition between hillslope and fluvial processes, proposed in various forms by Davis [1892], Gilbert [1909], Smith and Bretherton [1972] and others, and the erosion threshold of Horton [1945] influence the form of ridge-and-valley topography considerably. We find, however, that the former is the more important control on valley spacing. Although the introduction of an erosion threshold diminishes the stream incision term, even reducing it to zero where drainage area and slope are small, the resulting increase in slope mitigates the effect on valley spacing.

[76] The occurrence of uniform valley spacing affords an opportunity to compare model predictions of long-term landscape evolution with a prominent, measurable signal. The scaling arguments presented here, which yield relatively simple expressions for valley spacing and drainage basin relief, offer a basis for such a comparison.

[77] Acknowledgments. Conversations with Alan Howard are gratefully acknowledged. We thank the Orradre family of San Ardo, California, for granting access to their land. This work was supported by the Institute of Geophysics and Planetary Physics, NASA, an NSF Graduate Research Fellowship, and a Reginald A. Daly Postdoctoral Fellowship. Laser altimetry data for the Gabilan Mesa were acquired and processed by the National Center for Airborne Laser Mapping (NCALM, http://www.ncalm. org), with support from the National Center for Earth-surface Dynamics (NCED). Reviews by Greg Tucker, Alan Howard, Stephen Lancaster, and an anonymous referee improved the manuscript.

\section{References}

Abrahams, A., A. D. Howard, and A. Parsons (1994), Rock-mantled slopes, in Geomorphology of Desert Environments, edited by A. Abrahams and A. Parsons, pp. 173-211, Chapman and Hall, London.

Ahnert, F. (1976), Brief description of a comprehensive three-dimensional process-response model of landform development, Z. Geomorphol., 25, $29-49$.

Ahnert, F. (1987), Process-response models of denudation at different spatial scales, Catena Suppl., 10, 31-50.

Allen, P. (2005), Striking a chord, Nature, 434, 961, doi:10.1038/434961a. Bagnold, R. A. (1941), The Physics of Blown Sand and Desert Dunes, Methuen, London.
Bull, W. B. (1975), Allometric change of landforms, Geol. Soc. Am. Bull., $86(11), 1489-1498$.

Carson, M. A., and M. J. Kirkby (1972), Hillslope Form and Process, Cambridge Univ. Press, New York.

Castelltort, S., and G. Simpson (2006), River spacing and drainage network growth in widening mountain ranges, Basin Res., 18(3), 267-276.

Church, M. (2003), What is a geomorphological prediction?, in Prediction in Geomorphology, Geophys. Monogr. Ser., vol. 135, edited by P. R. Wilcock and R. M. Iverson, pp. 183-194, AGU, Washington, D. C.

Church, M., and D. M. Mark (1980), On size and scale in geomorphology, Prog. Phys. Geogr., 4(3), 342-390.

Costa-Cabral, M. C., and S. J. Burges (1994), Digital elevation model networks (DEMON): A model of flow over hillslopes for computation of contributing and dispersal areas, Water Resour. Res., 30(6), 1681-1692. Culling, W. E. H. (1960), Analytical theory of erosion, J. Geol., 68(3), $336-344$

Culling, W. E. H. (1963), Soil creep and the development of hillside slopes, J. Geol., 71(2), 127-161.

Culling, W. E. H. (1965), Theory of erosion on soil-covered slopes, J. Geol., $73,230-254$.

Darwin, C. (1859), On the Origin of Species by Means of Natural Selection, or the Preservation of Favoured Races in the Struggle for Life, Murray, London.

Davis, W. M. (1992), The convex profile of badland divides, Science, 20, 245.

Densmore, A. L., M. A. Ellis, and R. S. Anderson (1998), Landsliding and the evolution of normal-fault-bounded mountains, J. Geophys. Res., 103, $15,203-15,219$

Dietrich, W. E., and T. Dunne (1993), The channel head, in Channel Network Hydrology, edited by K. Beven and M. J. Kirkby, pp. 175-219, John Wiley, New York.

Dietrich, W. E., and D. R. Montgomery (1998), Hillslopes, channels, and landscape scale, in Scale Dependence and Scale Invariance in Hydrology, edited by G. Sposito, pp. 30-60, Cambridge Univ. Press, Cambridge, U.K.

Dietrich, W. E., C. J. Wilson, D. R. Montgomery, J. McKean, and R. Bauer (1992), Erosion thresholds and land surface morphology, Geology, 20(8), $675-679$.

Dietrich, W. E., C. J. Wilson, D. R. Montgomery, and J. McKean (1993), Analysis of erosion thresholds, channel networks, and landscape morphology using a digital terrain model, J. Geol., 101(2), 259-278.

Dietrich, W. E., D. G. Bellugi, L. S. Sklar, J. D. Stock, A. M. Heimsath, and J. J. Roering (2003), Geomorphic transport laws for predicting landscape form and dynamics, in Prediction in Geomorphology, Geophys. Monogr. Ser, vol. 135, edited by P. R. Wilcock and R. M. Iverson, pp. 103-132, AGU, Washington, D. C.

Dunne, T. (1980), Formation and controls of channel networks, Prog. Phys. Geogr., 4, 211-239.

Dunne, T., and B. F. Aubry (1986), Evaluation of Horton's theory of sheetwash and rill erosion on the basis of field experiments, in Hillslope Processes, edited by A. D. Abrahams, pp. 31-53, Allen and Unwin, Winchester, Mass.

Eaton, G. P. (1982), The basin and range province: Origin and tectonic significance, Annu. Rev. Earth Planet. Sci., 10(1), 409-440.

Fernandes, N. F., and W. E. Dietrich (1997), Hillslope evolution by diffusive processes: The timescale for equilibrium adjustments, Water Resour. Res., 33(6), 1307-1318.

Freeman, T. G. (1991), Calculating catchment area with divergent flow based on a regular grid, Comput. Geosci., 17(3), 413-422.

Gilbert, G. K. (1877), Report on the Geology of the Henry Mountains, U. S. Govt. Print. Off., Washington, D. C.

Gilbert, G. K. (1909), The convexity of hilltops, J. Geol., 17(4), 344-350. Gioia, G., and F. A. Bombardelli (2002), Scaling and similarity in rough channel flows, Phys. Rev. Lett., 88(1), 014501, doi:10.1103/PhysRevLett. 88.014501 .

Hack, J. T. (1957), Studies of longitudinal stream profiles in Virginia and Maryland, U.S. Geol. Surv. Prof. Pap., 294-B.

Hack, J. T., and J. C. Goodlett (1960), Geomorphology and forest ecology of a mountain region in the central Appalachians, U.S. Geol. Surv. Prof., 347 .

Hallet, B. (1990), Spatial self-organization in geomorphology: from periodic bedforms and patterned ground to scale-invariant topography, Earth Sci. Rev., 29, 57-75.

Hanks, T. C., R. C. Bucknam, K. R. Lajoie, and R. E. Wallace (1984), Modification of wave-cut and faulting-controlled landforms, J. Geophys. Res., 89, 5771-5790.

Hanley, J. T. (1977), Fourier analysis of the Catawba Mountain knolls, Roanoke county, Virginia, Math. Geol., 9(2), 159-163.

Hasbargen, L. E., and C. Paola (2000), Landscape instability in an experimental drainage basin, Geology, 28(12), 1067-1070. 
Hoey, T. B., P. Bishop, and R. I. Ferguson (2003), Testing numerical models in geomorphology: How can we ensure critical use of model predictions?, in Prediction in Geomorphology, Geophys. Monogr. Ser. vol. 135, edited by P. R. Wilcock and R. M. Iverson, pp. 241-256, AGU, Washington, D. C.

Horton, R. E. (1945), Erosional development of streams and their drainage basins: Hydrophysical approach to quantitative morphology, Geol. Soc. Am. Bull., 56(3), 275-370.

Hovius, N. (1996), Regular spacing of drainage outlets from linear mountain belts, Basin Res., 8, 29-44.

Howard, A. D. (1994a), A detachment-limited model of drainage basin evolution, Water Resour. Res., 30(7), 2261-2286.

Howard, A. D. (1994b), Badlands, in Geomorphology of Desert Environments, edited by A. Abrahams and A. Parsons, pp. 213-242, Chapman and Hall, London.

Howard, A. D. (1997), Badland morphology and evolution: Interpretation using a simulation model, Earth Surf. Processes Landforms, 22(3), 211 227 .

Howard, A. D. (1998), Long profile development of bedrock channels: Interaction of weathering, mass wasting, bed erosion, and sediment transport, in Rivers Over Rock: Fluvial Processes in Bedrock Channels, Geophys. Monogr. Ser., vol. 107, pp. 297-319, AGU, Washington, D. C.

Howard, A. D. (1999), Simulation of gully erosion and bistable landforms, in Incised River Channels: Processes, Forms, Engineering and Management, edited by S. Darby and A. Simon, pp. 277-299, John Wiley, Chichester, U.K.

Howard, A. D., and G. Kerby (1983), Channel changes in badlands, Geol. Soc. Am. Bull., 94(6), 739-752.

Howard, A. D., W. E. Dietrich, and M. A. Seidl (1994), Modeling fluvial erosion on regional to continental scales, J. Geophys. Res., 99, 13,971$13,986$.

Izumi, N., and G. Parker (1995), Inception of channelization and drainage basin formation: Upstream-driven theory, J. Fluid Mech., 283, 341-363.

Izumi, N., and G. Parker (2000), Linear stability analysis of channel inception: Downstream-driven theory, J. Fluid Mech., 419, 239-262.

Kennedy, J. F. (1969), The formation of sediment ripples, dunes, and antidunes, Annu. Rev. Fluid Mech., 1(1), 147-168.

Kirkby, M. J. (1971), Hillslope process-response models based on the continuity equation, Inst. Br. Geogr. Spec. Publ., 3, 15-30.

Kirkby, M. J. (1980), The stream head as a significant geomorphic threshold, in Thresholds in Geomorphology, edited by D. R. Coates and J. D. Vitek, pp. 53-73, Allen and Unwin, Winchester, Mass.

Kirkby, M. J. (1986), A two-dimensional simulation model for slope and stream evolution, in Hillslope Processes, edited by A. D. Abrahams, pp. 203-222, Allen and Unwin, Winchester, Mass.

Kirkby, M. J. (1987), Modelling some influences of soil erosion, landslides and valley gradient on drainage density and hollow development, Catena Suppl., 10, 1-14.

Kirkby, M. J. (1993), Long term interactions between networks and hillslopes, in Channel Network Hydrology, edited by K. Beven and M. J. Kirkby, pp. 255-293, John Wiley, New York.

Kirkby, M. J. (1994), Thresholds and instability in stream head hollows: A model of magnitude and frequency for wash processes, in Process Models and Theoretical Geomorphology, edited by M. J. Kirkby, pp. 295314, John Wiley, New York.

Knighton, D. (1998), Fluvial Forms and Processess: A New Perspective, Hodder Arnold, London.

Kooi, H., and C. Beaumont (1996), Large-scale geomorphology: classical concepts reconciled and integrated with contemporary ideas via a surface processes model, J. Geophys. Res., 101(B2), 3361-3386.

Leopold, L. B., and T. Maddock (1953), The hydraulic geometry channels and some physiographic implications, U.S. Geol. Surv. Prof. Pap., 252.

Loewenherz, D. S. (1991), Stability and the initiation of channelized surface drainage: A reassessment of the short wavelength limit, J. Geophys. Res., 96, 8453-8464.

Loewenherz-Lawrence, D. S. (1994), Hydrodynamic description for advective sediment transport processes and rill initiation, Water Resour. Res. $30(11), 3203-3212$.

Luke, J. C. (1972), Mathematical models of landform evolution, J. Geophys. Res., 77, 2,460-2,464.

Luke, J. C. (1974), Special solutions for nonlinear erosion problems, J. Geophys. Res., 79, 4035-4040.

Luke, J. C. (1976), A note on the use of characteristics in slope evolution models, Z. Geomorphol., Suppl., 25, 114-119.

Malin, M. C., and K. S. Edgett (2000), Evidence for recent groundwater seepage and surface runoff on mars, Science, 288(5475), 2330-2335.

McKean, J. A., W. E. Dietrich, R. C. Finkel, J. R. Southon, and M. W. Caffee (1993), Quantification of soil production and downslope creep rates from cosmogenic ${ }^{10} \mathrm{Be}$ accumulations on a hillslope profile, Geology, 21(4), 343-346.
Melton, M. A. (1958), Geometric properties of mature drainage systems and their representation in an E4 phase space, J. Geol., 66(1), 35-54.

Moglen, G. E., and R. L. Bras (1995), The effect of spatial heterogeneities on geomorphic expression in a model of basin evolution, Water Resour. Res., 31(10), 2613-2623.

Moglen, G. E., E. A. B. Eltahir, and R. L. Bras (1998), On the sensitivity of drainage density to climate change, Water Resour. Res, 34(4), 855-862.

Monaghan, M. C., J. McKean, W. Dietrich, and J. Klein (1992), ${ }^{10} \mathrm{Be}$ chronometry of bedrock-to-soil conversion rates, Earth Planet. Sci. Lett., $111,483-492$.

Montgomery, D. R., and W. E. Dietrich (1988), Where do channels begin?, Nature, 336, 232-234.

Montgomery, D. R., and W. E. Dietrich (1989), Source areas, drainage density, and channel initiation, Water Resour. Res., 25(8), 1907-1918.

Montgomery, D. R., and W. E. Dietrich (1992), Channel initiation and the problem of landscape scale, Science, 255(5046), 826-830.

Nash, D. (1980), Morphologic dating of degraded normal fault scarps, J. Geol., 88, 353-360.

O'Callaghan, J. F., and D. M. Mark (1984), The extraction of drainage networks from digital elevation data, Comput. Vision Graph. Image Process., 28(3), 323-344.

Orange, D. L., R. S. Anderson, and N. A. Breen (1994), Regular canyon spacing in the submarine environment: the link between hydrology and geomorphology, GSA Today, 4(2), 35-39.

Parsons, A. J., and A. D. Abrahams (1992), Field investigations of sediment removal in interrill overland flow, in Overland Flow: Hydraulics and Erosion Mechanics, edited by A. J. Parsons and A. D. Abrahams, pp. 307-334, Chapman and Hall, New York.

Parsons, A. J., A. D. Abrahams, and J. Wainwright (1994), On determining resistance to interrill overland flow, Water Resour. Res., 30(12), 35153522 .

Pelletier, J. D. (2004), Persistent drainage migration in a numerical landscape evolution model, Geophys. Res. Lett., 31, L20501, doi:10.1029/ 2004GL020802.

Perron, J. T., W. E. Dietrich, A. D. Howard, J. A. McKean, and J. R. Pettinga (2003), Ice-driven creep on Martian debris slopes, Geophys. Res. Lett., 30(14), 1747, doi:10.1029/2003GL017603.

Perron, J. T., J. W. Kirchner, and W. E. Dietrich (2008), Spectral signatures of characteristic spatial scales and nonfractal structure in landscapes, J. Geophys. Res., 113, F04003, doi:10.1029/2007JF000866.

Press, W. H., S. A. Teukolsky, W. T. Vetterling, and B. P. Flannery (1992), Numerical Recipes in C: The Art of Scientific Computing, Cambridge Univ. Press, New York.

Prosser, I. P., and W. E. Dietrich (1995), Field experiments on erosion by overland flow and their implication for a digital terrain model of channel initiation, Water Resour. Res., 31(11), 2867-2876.

Quinn, P., K. Beven, P. Chevallier, and O. Planchon (1991), The prediction of hillslope flow paths for distributed hydrological modelling using digital terrain models, Hydrol. Processes, 5(1), 59-79.

Reid, L. M. (1989), Channel incision by surface runoff in grassland catchments, Ph.D. thesis, Univ. of Washington, Seattle.

Rinaldo, A., W. E. Dietrich, R. Rigon, G. K. Vogel, and I. Rodriguez-Iturbe (1995), Geomorphological signatures of varying climate, Nature, 374, $632-635$.

Roering, J. J., J. W. Kirchner, and W. E. Dietrich (1999), Evidence for nonlinear, diffusive sediment transport on hillslopes and implications for landscape morphology, Water Resour. Res., 35(3), 853-870.

Roering, J. J., J. W. Kirchner, and W. E. Dietrich (2001a), Hillslope evolution by nonlinear, slope-dependent transport: Steady state morphology and equilibrium adjustment timescales, J. Geophys. Res., 106, 16,49916,514 .

Roering, J. J., J. W. Kirchner, L. S. Sklar, and W. E. Dietrich (2001b), Hillslope evolution by nonlinear creep and landsliding: An experimental study, Geology, 29(2), 143-146.

Roering, J. J., J. T. Perron, and J. W. Kirchner (2007), Functional relationships between denudation and hillslope form and relief, Earth Planet. Sci. Lett., 264, 245-258.

Rosenbloom, N. A., and R. S. Anderson (1994), Hillslope and channel evolution in a marine terraced landscape, Santa Cruz, California, J. Geophys. Res., 99, 14,013-14,029.

Schorghofer, N., B. Jensen, A. Kudrolli, and D. H. Rothman (2004), Spontaneous channelization in permeable ground: theory, experiment, and observation, J. Fluid Mech., 503, 357-374.

Seidl, M. A., and W. E. Dietrich (1992), The problem of channel erosion into bedrock, in Functional Geomorphology, edited by K. Schmidt and J. de Ploey, Catena Suppl., 23, 101-124.

Seidl, M. A., W. E. Dietrich, and J. W. Kirchner (1994), Longitudinal profile development into bedrock: An analysis of Hawaiian channels, J. Geol., 102(4), 457-474. 
Shaler, N. S. (1899), Spacing of rivers with reference to the hypothesis of base-levelling, Geol. Soc. Am. Bull., 10, 263-276.

Shreve, R. L. (1967), Infinite topologically random channel networks, J. Geol., 75, 178-186.

Simpson, G., and F. Schlunegger (2003), Topographic evolution and morphology of surfaces evolving in response to coupled fluvial and hillslope sediment transport, J. Geophys. Res., 108(B6), 2300, doi:10.1029/ 2002JB002162.

Sklar, L., and W. E. Dietrich (1998), River longitudinal profiles and bedrock incision models: Stream power and the influence of sediment supply, in Rivers Over Rock: Fluvial Processes in Bedrock Channels, Geophys. Monogr. Ser., vol. 107, edited by K. Tinkler and E. Wohl, pp. 237-260, AGU, Washington, D. C.

Small, E. E., R. S. Anderson, and G. S. Hancock (1999), Estimates of the rate of regolith production using ${ }^{10} \mathrm{Be}$ and ${ }^{26} \mathrm{Al}$ from an alpine hillslope, Geomorphology, 27(1), 131-150.

Smith, T. R., and F. P. Bretherton (1972), Stability and the conservation of mass in drainage basin evolution, Water Resour. Res., 8(6), 1506-1529.

Smith, T. R., and G. E. Merchant (1995), Conservation principles and the initiation of channelized surface flows, in Natural and anthropogenic influences in fluvial geomorphology, Geophys. Monogr. Ser., vol. 89, edited by A. J. Miller, K. W. Potter, and P. R. Wilcock, pp. 1-25, AGU, Washington, D. C.

Smith, T. R., B. Birnir, and G. E. Merchant (1997a), Towards an elementary theory of drainage basin evolution: I. The theoretical basis, Comput. Geosci., 23(8), 811-822.

Smith, T. R., G. E. Merchant, and B. Birnir (1997b), Towards an elementary theory of drainage basin evolution: II. A computational evaluation, Compute. Geosci., 23(8), 823-849.

Snyder, N. P., K. X. Whipple, G. E. Tucker, and D. J. Merritts (2003), Importance of a stochastic distribution of floods and erosion thresholds in the bedrock river incision problem, J. Geophys. Res., 108(B2), 2117, doi:10.1029/2001JB001655.

Stock, J., and W. E. Dietrich (2003), Valley incision by debris flows: Evidence of a topographic signature, Water Resour. Res., 39(4), 1089, doi:10.1029/2001WR001057.

Stock, J., and W. Dietrich (2006), Erosion of steepland valleys by debris flows, Geol. Soc. Am. Bull., 118(9), 1125-1148.

Stock, J. D., D. R. Montgomery, B. D. Collins, W. E. Dietrich, and L. Sklar (2005), Field measurements of incision rates following bedrock exposure: Implications for process controls on the long profiles of valleys cut by rivers and debris flows, Geol. Soc. Am. Bull., 117, 174-194.

Strahler, A. N. (1958), Dimensional analysis applied to fluvially eroded landforms, Geol. Soc. Am. Bull., 69, 279-300.

Strahler, A. N. (1964), Quantitative geomorphology of drainage basins and channel networks, in Handbook of Applied Hydrology, edited by V. T. Chow, pp. 4.39-4.76, McGraw-Hill, New York.

Syvitski, J. P., and M. D. Morehead (1999), Estimating river-sediment discharge to the ocean: Application to the eel margin, northern california Mar. Geol., 154(1), 13-28.

Talling, P. J., and M. J. Sowter (1999), Drainage density on progressively tilted surfaces with different gradients, Wheeler Ridge, California, Earth Surf. Processes Landforms, 24(9), 809-824.

Talling, P. J., M. D. Stewart, C. P. Stark, S. Gupta, and S. J. Vincent (1997), Regular spacing of drainage outlets from linear fault blocks, Basin Res., 9, 275-302.
Tarboton, D. G. (1997), A new method for the determination of flow directions and upslope areas in grid digital elevation models, Water Resour. Res., 33(2), 309-319.

Tarboton, D., R. L. Bras, and I. Rodriguez-Iturbe (1989), Scaling and elevation in river networks, Water Resour. Res., 25(9), 2037-2051.

Tarboton, D. G., R. L. Bras, and I. Rodriguez-Iturbe (1992), A physical basis for drainage density, Geomorphology, 5(1-2), 59-76.

Tucker, G. E., and R. L. Bras (1998), Hillslope processes, drainage density, and landscape morphology, Water Resour. Res., 34(10), 2751-2764.

Tucker, G. E., and R. Slingerland (1996), Predicting sediment flux from fold and thrust belts, Basin Res., 8(3), 329-349.

Tucker, G. E., and R. Slingerland (1997), Drainage basin responses to climate change, Water Resour. Res., 33(8), 2031-2047.

Tucker, G. E., and K. X. Whipple (2002), Topographic outcomes predicted by stream erosion models: Sensitivity analysis and intermodel comparison, J. Geophys. Res., 107(B9), 2179, doi:10.1029/2001JB000162.

van der Beek, P., and J. Braun (1998), Numerical modelling of landscape evolution on geological time-scales: A parameter analysis and comparison with the south-eastern highlands of Australia, Basin Res., 10, 49 68 .

Whipple, K. X., and G. E. Tucker (1999), Dynamics of the stream-power river incision model: Implications for height limits of mountain ranges, landscape response timescales, and research needs, J. Geophys. Res., 104(B8), 17,661-17,674

Willgoose, G. (1994a), A statistic for testing the elevation characteristics of landscape simulation models, J. Geophys. Res., 99(B7), 13,987-13,996

Willgoose, G. (1994b), A physical explanation for an observed area-slopeelevation relationship for catchments with declining relief, Water Resour. Res., 30(2), 151-160.

Willgoose, G. (2005), Mathematical modeling of whole landscape evolution, Annu. Rev. Earth Planet. Sci., 33(1), 443-459.

Willgoose, G., R. L. Bras, and I. Rodriguez-Iturbe (1991a), Results from a new model of river basin evolution, Earth Surf. Processes Landforms, 16(3), 237-254.

Willgoose, G., R. L. Bras, and I. Rodriguez-Iturbe (1991b), A coupled channel network growth and hillslope evolution model: 1 . Theory, Water Resour. Res., 27(7), 1671-1684.

Willgoose, G., R. L. Bras, and I. Rodriguez-Iturbe (1991c), A coupled channel network growth and hillslope evolution model: 2 . Nondimensionalization and applications, Water Resour. Res., 27(7), 1685-1696.

Willgoose, G., R. L. Bras, and I. Rodriguez-Iturbe (1991d), A physical explanation of an observed link area-slope relationship, Water Resour. Res., 27(7), 1697-1702.

Willgoose, G., R. L. Bras, and I. Rodriguez-Iturbe (1992), The relationship between catchment and hillslope properties: implications of a catchment evolution model, Geomorphology, 5(1-2), 21-37.

Willgoose, G. R., G. R. Hancock, and G. Kuczera (2003), A framework for the quantitative testing of landform evolution models, in Prediction in Geomorphology, Geophys. Monogr. Ser., vol. 135, edited by P. R. Wilcock and R. M. Iverson, pp. 195-216, AGU, Washington, D. C.

W. E. Dietrich and J. W. Kirchner, Department of Earth and Planetary Science, University of California, 307 McCone Hall, Berkeley, CA 94720 USA.

J. T. Perron, Department of Earth, Atmospheric and Planetary Sciences, Massachusetts Institute of Technology, Cambridge, MA 02139, USA. (perron@mit.edu) 